Max-Planck-Institut für demografische Forschung

Max Planck Institute for Demographic Research

Doberaner Strasse 114 - D-18057 Rostock · GERMANY

Tel +49 (0) 3812081 - 0; Fax +49 (0) 3812081 - 202;

http://www.demogr.mpg.de

MPIDR WORKING PAPER WP 2001-032

OCTOBER 2001

\title{
Towards a Theory of \\ Lowest-Low Fertility
}

Hans-Peter Kohler (kohler@demogr.mpg.de)

Francesco C. Billari (billari@ demogr.mpg.de)

José Antonio Ortega (joseantonio.ortega@uam.es)

(C) Copyright is held by the authors.

Working papers of the Max Planck Institute for Demographic Research receive only limited review. Views or opinions expressed in working papers are attributable to the authors and do not necessarily reflect those of the Institute. 


\title{
Towards a Theory of Lowest-Low Fertility
}

\author{
Hans-Peter Kohler* Francesco C. Billari ${ }^{\dagger} \quad$ José Antonio Ortega $^{\ddagger}$
}

October 17, 2001

\begin{abstract}
Lowest-low fertility, defined as a period total fertility rate below 1.3, has rapidly spread in Europe during the 1990s and is likely to expand further. In this paper we argue that the emergence and persistence of this new phenomenon is due to the combination and interaction of four factors. First, tempo- and compositional distortions reduce the TFR below the associated level of cohort fertility, and these distortions can be quantified with appropriate adjusted measures. Second, late childbearing has become a rational response to increased returns to human capital and high economic uncertainty in early adulthood. Third, social interaction reinforces the behavioral adjustment of individuals, and it can lead to postponement transitions with large and persistent changes in the mean age at birth. Fourth, delayed childbearing is associated with postponement-quantum interactions that reduce completed fertility. We conclude the paper with some speculations about future trends in lowest-low fertility countries and candidates.
\end{abstract}

\section{Introduction}

Low fertility has become quite commonplace worldwide, and Europe has experienced below replacement fertility for several decades. Yet, demographers are quite puzzled by a recent phenomenon in fertility trends: lowest-low fertility. We define lowest-low fertility as a period total fertility rate below 1.3. Italy and Spain were the first countries to experience a persistent drop of the TFR below 1.3, and the group of countries with a TFR below 1.3 has been rapidly growing throughout the 1990s. There are currently 14 lowest-low fertility countries, and these countries are concentrated in Southern, Central and Eastern Europe and among the former Soviet Republics. Several additional countries in Europe and East Asia can be considered as 'candidates', and the group of lowest-low fertility countries is likely to expand in the next decade.

\footnotetext{
${ }^{*}$ Head of Research Group on Social Dynamics and Fertility, Max Planck Institute for Demographic Research, Doberaner Str. 114, 18057 Rostock, Germany. Tel: +49-381-2081-123, Fax: +49-381-2081-423, Email: kohler@demogr.mpg.de,www: http://user.demogr.mpg.de/kohler.

${ }^{\dagger}$ Head of Research Group on the Demography of Early Adulthood, Max Planck Institute for Demographic Research, Doberaner Str. 114, 18057 Rostock, Germany. Tel: +49-381-2081-184, Fax: +49-3812081-484, Email: kohler@demogr.mpg.de, www: http://user.demogr.mpg.de/billari.

${ }^{\ddagger}$ Departamento de Análisis Económico: Economía Cuantitativa, Universidad Autónoma de Madrid, 28049-Madrid, Spain, Email: joseantonio.ortega@uam.es, www: http://www.adi.uam.es/ jaortega.
} 
Levels of the total fertility rate below 1.3 are clearly not a demographic equilibrium, and sustained lowest-low fertility implies far-reaching demographic, economic and social consequences. For instance, a TFR of 1.3 implies an annual decline of the population size by $1.5 \%$ in a stable population with an overall mean age at birth of 30 years. A TFR of 1.3 also implies a reduction of the birth cohort by $50 \%$ and a halving of the stable population size every 45 years. ${ }^{1}$ If the TFR further declines and persists at a level of one, the annual rate of decline in the stable population rises to $2.4 \%$ and the halvingtimes of population size and birth cohorts are merely 30 years. This substantially faster decline of the population also reveals that the precision of demographic measures becomes increasingly important in lowest-low fertility contexts: a difference in the TFR between 1.0 and 1.3 is equivalent to the difference between 3.2 and 4.2 in terms of stable population growth rates.

In this paper we start to develop a theory of lowest-low fertility that provides a conceptual framework for $(a)$ analyzing the emergence and persistence of lowest-low fertility levels in Europe and other parts of the world, and (b) discussing future scenarios for fertility trends in lowest-low fertility countries and lowest-low 'candidates'. We argue that lowest-low fertility is due to the combination of four distinct demographic and behavioral factors. First, demographic distortions of period fertility measures, caused by the postponement of fertility and changes in the parity-composition of the population, reduce the level of period-fertility indicators below the associated level of cohort fertility. Second, economic and social changes have made the postponement of fertility and a low progression to higher parities a rational response for individuals. Third, perpetuating mechanisms, and in particular social interaction processes affecting the timing of fertility, render the population response to these new socioeconomic conditions substantially larger than the direct individual responses. Modest or path-dependent socioeconomic changes can therefore lead to a rapid and persistent postponement transition from early to late age-patterns of fertility. Fourth and finally, postponement-quantum interactions imply that these changes in the timing of fertility not only lead to delayed childbearing, but also have causal effects on parity-progression probabilities and completed fertility.

\section{Historical Antecedents of Lowest-Low Fertility}

Low fertility is not strictly a new phenomenon. In all known cases of population extinction we can certainly talk of below-replacement fertility. In almost every case the main driving force was a high mortality rate that substantially increased replacement fertility levels. ${ }^{2}$ Due to high levels of mortality, we also cannot expect sustained total fertility levels below two until relatively recent periods. In the European context, low fertility was first adopted as an intentional low-reproduction strategy by the nobility and the upper classes. Still, low fertility was not the main element for achieving low reproduction: the generally adopted rule consisted of marrying only a subset of the siblings, usually the eldest of each sex, in order to avoid the partition of family property and to maintain family status (Johansson 1987). In the $19^{\text {th }}$ century, low fertility strategies were increasingly adopted by the bourgeoisie and land-owners leading to low fertility levels in many subpopulations, gradually 
spreading to other social classes (Haines 1992). Despite this spread of low fertility within subpopulations, the absolute fertility level remained relatively high. The lowest national fertility level at the turn of the century prevailed in France with a TFR of 2.79 (Festy 1979). There was not a single European province with a total fertility level below two, ${ }^{3}$ and one needs to look at subpopulations such as the urban native-born whites in the United States to find below-replacement fertility levels (Sanderson 1991).

The postponement and anticipation of marriage and fertility are similarly not a new phenomenon. The countries with relatively low fertility at the turn of the $20^{\text {th }}$ century were also characterized by a late marriage pattern (Hajnal 1965, 1982). In particular, a flexible age at marriage was a very common response to socioeconomic changes in Northern and Western Europe: in times of economic upturns marriage was anticipated, and it was delayed in periods of economic downturn. For instance, the generations born in the second part of the $19^{\text {th }}$ century in many areas of Northern and Western Europe were postponing marriage between one and 2.5 years (Festy 1979). This flexible timing of marriage lead to characteristic cyclical movements in marriage rates connected to economic circumstances which partly caused the corresponding movements in birth rates (Lee 1997). Reduced fertility was therefore often associated with delayed marriage and delayed first birth.

In the interwar period, Europe witnessed for the first time national fertility falling below two, raising considerable concern about depopulation (Glass 1936; Teitelbaum and Winter 1985). At the same time, there was no case of a national TFR below 1.5. Fertility below this level prevailed only at the local scale. In particular, patterns of lowest-low fertility emerged for the first time in cities such as Vienna, Stockholm or Berlin. According to the Princeton Fertility Study, there were a total of nine lowest-low fertility districts in Europe in 1930. These regions were mostly urban areas, and some of them attained TFR levels that were substantially below one (e.g., a TFR of 0.63 in Vienna). ${ }^{4}$

After WWII and the postwar baby boom, a widespread decline of fertility to levels below two was initiated in Western Europe, and the primary exceptions to this trend were concentrated in Southern Europe. Despite this nearly universal decline in birth rates, the emergence and persistence of lowest-low fertility was outside the scenarios discussed by demographers. For instance, in the seventies Bourgeois-Pichat $(1976,1979)$ proposed a TFR of 1.5 as the minimal level at which fertility reaches its low point and subsequently stabilizes or even reverses. While the specific level of 1.5 may not have been universally agreed upon as the ultimate trough in fertility declines, similar perceptions of a stabilization at - or just below - replacement level have nevertheless permeated many areas of demographic applications and discussions. Well-known examples of this perception are the common idea of the demographic transition as a movement between regimes with approximate demographic stability, and the fact that the UN population projections during the 1990s assumed a convergence towards replacement fertility in all the countries by 2050 (United Nations 1996, 1999). 


\section{Measurement issues: Characterizing lowest-low fertility}

The emergence and persistence of lowest-low fertility in the 1990s is in sharp contrast to the above notions of a stabilization of fertility levels near a TFR of 2.1. The analysis of this pattern therefore requires a rethinking of many conceptions and ideas that have become familiar to demographers and other observers of contemporary fertility trends. In particular, we argue that the analysis of lowest-low fertility demands first and foremost a careful demographic investigation that disentangles compositional and tempo distortions from the observed trends in the total fertility rate and other indicators of period fertility. Once these demographic factors contributing to lowest-low fertility are quantified, the components of individual's fertility responses to new socioeconomic conditions - i.e., changes in the timing and quantum of childbearing - can be identified. These components of fertility change are then amenable to explanations through behavioral theories of fertility. In particular, once demographic distortions are removed from period fertility indicators, these measures provide information that can be related to the socioeconomic conditions and transformations that have affected and altered individual's decisions about the timing and level of fertility.

\subsection{Defining and measuring lowest-low fertility}

The choice of a threshold to define lowest-low fertility is to a certain extent arbitrary. Our choice of 1.3 serves to differentiate the extremely low levels of fertility that started to appear primarily in the last decade. TFR levels below 1.3 never prevailed for extended periods in the Northern and Western European countries that were the forerunners in the trend towards sustained below-replacement fertility. In particular, the only incidences of lowest-low fertility on a national level in Northern and Western Europe were temporary and occurred in France during World War I, West Germany in 1984-85, and the unified Germany in 1993-95. ${ }^{5}$ The influence of these early lowest-low fertility episodes on cohort fertility was relatively mute. For instance, French cohort fertility reached a minimum just below two for the generation born in 1895 (Festy 1984), and the West German total fertility rate has slightly increased and apparently stabilized at a level around 1.4.

The emergence of sustained lowest-low fertility first occurs in the Southern, Central and Eastern European (CEE) countries. Based on 1999 fertility levels (Council of Europe 2000), there are 14 lowest-low fertility countries (Table 1): three in Southern Europe (Spain, Italy and Greece), five in Central and Eastern Europe (Bulgaria, Czech Republic, Hungary, Romania, Slovenia) and seven in the former Soviet Union (Estonia, Latvia, Russia, Ukraine, Belarus, Georgia and Armenia). The first countries to reach lowest-low fertility levels were Spain and Italy in 1992 and 1993 respectively. They were then joined by Bulgaria, Slovenia and Latvia in 1995, and the rest of countries between that date and 1999. The remaining countries in Eastern Europe and the Balkans also have very low fertility levels, and countries such as Poland (1.37), Lithuania (1.35), the Slovak Republic (1.33) or Croatia (1.38) will possibly join the list of lowest-low fertility countries soon. Germany (1.36) and Austria (1.32), representing two traditional low fertility countries, are also likely to join the list. Moreover, lowest-low fertility is likely to spread to East 
Table 1: Fertility in the lowest-low fertility countries and 'candidates' during 1985-99

\begin{tabular}{|c|c|c|c|c|c|}
\hline \multirow[b]{2}{*}{ Country } & \multicolumn{3}{|c|}{ TFR } & \multicolumn{2}{|c|}{$\begin{array}{l}\text { Year TFR most } \\
\text { recently fell }\end{array}$} \\
\hline & 1985 & 1990 & 1999 & $<2$ & $<1.3$ \\
\hline Greece & 1.67 & 1.39 & 1.3 & 1983 & 1998 \\
\hline Italy & 1.42 & 1.33 & 1.19 & 1977 & 1993 \\
\hline Spain & 1.64 & 1.36 & 1.2 & 1982 & 1992 \\
\hline Bulgaria & 1.98 & 1.82 & 1.23 & 1985 & 1995 \\
\hline Czech R & 1.96 & 1.9 & 1.13 & 1982 & 1996 \\
\hline Estonia & 2.12 & 2.04 & 1.24 & 1991 & 1997 \\
\hline Hungary & 1.85 & 1.87 & 1.29 & 1980 & 1999 \\
\hline Latvia & 2.09 & 2.01 & 1.16 & 1991 & 1995 \\
\hline Romania & 2.32 & 1.84 & 1.3 & 1990 & 1999 \\
\hline Slovenia & 1.71 & 1.46 & 1.21 & 1981 & 1995 \\
\hline Armenia & 6.55 & 2.63 & 1.2 & 1993 & 1999 \\
\hline Belarus & 2.07 & 1.91 & 1.29 & 1990 & 1997 \\
\hline Georgia & 2.26 & 2.2 & 1.07 & 1992 & 1997 \\
\hline Russia & 2.05 & 1.9 & 1.17 & 1990 & 1996 \\
\hline Ukraine & 2.02 & 1.89 & $1.19^{*}$ & 1989 & 1997 \\
\hline Croatia & 1.81 & 1.67 & 1.38 & 1968 & \\
\hline Lithuania & 2.08 & 2.02 & 1.35 & 1991 & \\
\hline Poland & 2.32 & 2.05 & 1.37 & 1992 & \\
\hline Slovakia & 2.26 & 2.09 & 1.33 & 1992 & \\
\hline Austria & 1.47 & 1.45 & 1.32 & 1973 & \\
\hline Germany & 1.37 & 1.45 & 1.36 & 1971 & \\
\hline Japan & 1.76 & 1.54 & $1.38^{*}$ & 1975 & \\
\hline Korea & 1.67 & 1.59 & 1.42 & 1984 & \\
\hline
\end{tabular}

Notes: Data indicated with * correspond to the year 1998. Sources: Council of Europe, 2001; except: Japan (Statistics Bureau \& Statistics Center 2001) and Korea (Korean National Statistical Office 2001). 
Asia. The regions of Hong-Kong and Macao already have lowest-low fertility levels, and countries like Japan (1.4) and the Republic of Korea (1.5) are likely to follow this trend in the near future.

While the focus on period total fertility provides an easy classification of lowest-low fertility, it can also be misleading because of important measurement issues. In particular, the TFR constitutes a period fertility measure that is subject to tempo and compositional influences. Tempo distortions occur during periods when fertility is either postponed or anticipated, and these distortions have been much emphasized in recent discussions (Bongaarts and Feeney 1998; Kohler and Ortega 2001b; Kohler and Philipov 2001).

In all lowest-low fertility countries the mean age at first birth is higher in 1998/99 than in 1990 (see Table 2). In the Southern European countries, postponement has been very intense with annual increases in the mean age exceeding 0.2 per year. Combined with a relatively high initial mean age, this postponement has lead to some of the highest mean ages worldwide. In the CEE countries, the patterns are not so uniform. Extremely fast postponement has occurred in Slovenia, the Czech Republic and Hungary. Other countries, like Bulgaria, Estonia, Latvia and Romania, have experienced moderate postponement with increases in the mean age at first birth around 0.1 per year, and these countries continue to have a very young mean age. Similar patterns also prevail in other countries of the former Soviet Union like Russia, Belarus and Armenia (and presumably also Ukraine, where the respective data are not available).

A second demographic factor that influences the period total fertility rate is the composition of the population by parity. If a recent decline of fertility is concentrated on higher birth orders, the observed population parity composition in the short- and medium term is tilted towards high parities as compared to the equilibrium distribution that would prevail in the long-term after fertility rates have stabilized. ${ }^{6}$ This difference in the observed versus the equilibrium distribution occurs because the observed parity distribution in the population reflects past - and not present - fertility behaviors and trends. The same disequilibrium in the parity distribution occurs after a substantial postponement of fertility. Unfortunately, the commonly used TFR is affected by such fluctuations in the parity distribution of the population. In particular, if one holds the parity- and age-specific birth intensities constant (or equivalently, age-specific parity-progression probabilities), the TFR is lower when fertility has recently declined or has recently been postponed. This is due to the fact that women who are exposed to lower-parity births are underrepresented in the population. If fertility stabilizes, these compositional distortions diminish and the observed TFR converges to the equilibrium level.

In order to show the contribution of the parity composition to period fertility, it is therefore useful to compare the observed TFR with the level that would have been observed in equilibrium. The latter can be computed from calculations based on period parity progression rates, and Kohler and Ortega (2001b) show how these calculations can be combined with tempo adjustment. Unfortunately, the data requirements for these calculations are more intense. Therefore the only measure of tempo which is available for almost all the lowest-low countries is the traditional mean age at first-birth, calculated from fertility rates of the second kind (table 2). For specific countries, however, we can 
Table 2: Fertility timing in lowest-low fertility countries and 'candidates', year of onset of the postponement transition, and fertility of the 1965 cohort

\begin{tabular}{|c|c|c|c|c|c|c|}
\hline \multirow[b]{2}{*}{ Country } & \multicolumn{2}{|c|}{ MAFB } & \multirow{2}{*}{$\begin{array}{c}\text { Difference } \\
1990-99\end{array}$} & \multirow{2}{*}{$\begin{array}{c}\text { Year of } \\
\text { Onset }\end{array}$} & \multirow{2}{*}{\multicolumn{2}{|c|}{$\begin{array}{l}\text { Estimated } \\
\text { Fertility of } \\
\text { Cohort } \\
1965\end{array}$}} \\
\hline & 1990 & 1999 & & & & \\
\hline Greece & 25.5 & $27.2^{*}$ & 1.7 & 1982 & 1.71 & \\
\hline Italy & 26.9 & $28.4 \dagger$ & 1.5 & 1976 & 1.57 & \\
\hline Spain & 26.8 & $28.9^{*}$ & 2.1 & 1979 & 1.63 & (1963 coh) \\
\hline Bulgaria & 22.2 & 23.0 & 0.8 & 1992 & 1.82 & \\
\hline Czech R & 22.5 & 24.6 & 2.1 & 1991 & 1.91 & \\
\hline Estonia & 22.9 & 23.8 & 0.9 & 1993 & 1.82 & \\
\hline Hungary & 23.1 & 24.8 & 1.7 & 1990 & 1.95 & \\
\hline Latvia & 23.0 & 24.2 & 1.2 & 1992 & & \\
\hline Romania & 22.6 & 23.5 & 0.9 & 1993 & 1.91 & \\
\hline Slovenia & 23.7 & 26.1 & 2.4 & 1986 & 1.75 & \\
\hline Armenia & 22.9 & 22.9 & 0.0 & 1995 & & \\
\hline Belarus & 22.6 & 22.7 & 0.1 & Not yet & & \\
\hline Georgia & & & & & & \\
\hline $\begin{array}{l}\text { Russia } \\
\text { Ukraine }\end{array}$ & 22.6 & $23.0 \ddagger$ & 0.4 & 1994 & 1.66 & \\
\hline Croatia & 24.1 & 25.4 & 1.3 & 1975 & 1.85 & \\
\hline Lithuania & 23.2 & 23.7 & 0.5 & 1994 & 1.68 & \\
\hline Poland & 23.3 & 24.2 & 0.9 & 1991 & 2.00 & \\
\hline Slovakia & 22.6 & 23.8 & 1.2 & 1991 & 2.02 & \\
\hline Austria & 25.0 & 26.3 & 1.3 & & 1.60 & \\
\hline Germany & 26.6 & 27.9 & 1.3 & 1972 & 1.54 & \\
\hline $\begin{array}{l}\text { Japan } \\
\text { Korea }\end{array}$ & 27.2 & & & & 1.68 & (1962 coh) \\
\hline
\end{tabular}


calculate the more sophisticated measures based on childbearing intensities or rates of the first kind. ${ }^{7}$ These measures, discussed in more detail below, are not affected by fluctuations in the parity composition of the population.

One final methodological question in the context of recent fertility declines is the relevance of studying period fertility. Lowest-low fertility may not lead to particularly low cohort fertility if it is just a temporary phenomenon. In this case, fertility 'recuperates' at older ages (Frejka and Calot 2001a,b; Lesthaeghe and Moors 2000; Lesthaeghe and Willems 1999). ${ }^{8}$ The French experience after World War I is an example of this: the generations that would have had their children during WWI ended up having almost the same completed fertility as the other generations but at a later age. If lowest-low fertility is persistent, the potential for recuperation is more difficult to assess. It is likely to be much more difficult in Southern Europe where the onset of fertility is increasingly postponed to very late ages, leaving little time for catching up. The situation is somewhat different in the CEE countries, where cumulated fertility for currently young mothers is among the highest in Europe due to the relatively young pattern of childbearing. In 1999, for instance, the 1965 female cohort had by age 34 less than 1.6 children in Italy and Spain, whereas the same cohort in most of the lowest-low fertility countries in Central and Eastern Europe had already more than 1.8 children. The cases of Russia (1.66) and Slovenia (1.75) are midway. (Table 2; see also Frejka and Calot 2001a). The contrast is even more drastic for younger cohorts. Frejka and Calot (2001b) show the very large differences in fertility below 27 for the 1970-1971 cohort: whereas in all the CEE countries and former Soviet Republics the figures are always above one children, in Italy or Spain they are below 0.4.

Evidence on the scope for recuperation can also be obtained from micro-data. If there is a 'pure' postponement of fertility with perfect recuperation at later ages, and if we ignore for the moment issues of unobserved heterogeneity and selectivity, then the age at first birth should be only a weak predictor of an individual's completed fertility in simple regressions of fertility on the age at first birth. Independent of when women would start their reproductive careers, a pure postponement of fertility would imply that - on average - the completed fertility is approximately similar between early and late starters. Unfortunately, the empirical evidence is in contrast to this hypothesis of a 'pure' postponement. In particular, there exists a well-known negative association between the age at first birth and completed fertility (e.g., Bumpass and Mburugu 1977; Bumpass et al. 1978; Marini and Hodsdon 1981; Morgan and Rindfuss 1999; Presser 1971; Trussell and Menken 1978). Moreover, even after controlling for potentially important unobserved characteristics that determine both the age at first birth and completed fertility in a study of Danish MZ twins, Kohler et al. (2001) find that an additional year of delay in childbearing reduces completed fertility on average by $3 \%$ for females and $3.4 \%$ for males in cohorts born $1945-$ 60. Hence, there seems to be a negative postponement effect that causally links a later onset of childbearing to lower completed fertility. In some countries, including Denmark and the U.S., it has been observed that the relevance of these negative postponement effects has weakened over time. ${ }^{9}$ For instance, the estimates for Denmark in Kohler et al. (2001) show that the an additional year of delay in childbearing reduces completed fertility by $3.8-4.9 \%$ for cohorts $1945-52$, it decreases to about $1.7-1.85 \%$ for cohorts $1953-60$. 
This reduction in the extent of a negative postponement effect is an important aspect of why Denmark has achieved a high recuperation of delayed births: although the mean age at first birth increased by 2.8 years across merely 16 birth cohorts (from 23.5 in the 1945 cohort to 26.3 in the 1960 cohort), the completed cohort fertility declined only slightly from 2.06 to 1.89 (Eurostat 2001).

Some lowest-low fertility countries may provide important exceptions in this declining relevance of the onset of childbearing for completed fertility. Since the more sophisticated analyses performed on the basis of Danish MZ twins are not feasible in lowest-low countries, we perform simple regressions of the logarithm of fertility at age 38, which can be considered as almost completed fertility, on the age at first birth for women who experience their first birth prior to age 32. These estimates provide individual-level evidence about the importance of the onset of childbearing on completed fertility, and the regression coefficient - denoted as postponement effect - measures the relative decline in completed fertility associated with a one-year delay in the age at first birth. ${ }^{10}$

Table 3 shows the estimates of this postponement effect for some lowest-low fertility countries and for Sweden as a reference. In Italy and Spain the postponement effect is relatively high, and it implies a relative reduction of completed fertility between 2.9-5.1\% for each one-year delay in the onset of parenthood. For the youngest cohorts in the table, the postponement effects equal $2.9 \%$ for Italy and $3.8 \%$ for Spain. Despite its decline in the most recent cohorts, the postponement effect is still substantially above the levels in Denmark and Sweden, which represent countries with very successful recuperation. The Southern European lowest-low fertility countries thus exhibit a strong negative association between the onset and level of fertility. The Central and Eastern European cases differ from the Italian and Spanish situation in terms of a relatively small or moderate postponement effect that has been quite stable over time. This relatively small effect may be due to the young age-pattern of fertility in these cohorts, which provides more opportunities for women to recuperate after delaying their first birth.

The results in Table 3 therefore suggest important postponement-quantum interactions that are consistent with many related studies: late starters in childbearing tend to have lower fertility than early starters, and there does not seem to be a 'pure' postponement of fertility. Moreover, the lowest-low fertility countries in Southern Europe seem to exhibit a relatively strong negative association between the onset of childbearing and the level of fertility, and this postponement effect has not weakened substantially in more recent cohorts.

\subsection{Demographic Analysis of Lowest Low Fertility}

In this section we implement the methodological approach of Kohler and Ortega (2001b) in order to obtain estimates of the completed cohort fertility that is associated with currently observed levels of lowest-low period fertility. These calculations are based on childbearing intensities and can therefore eliminate both tempo and compositional distortions in period fertility measures.

Tempo adjustment was recently proposed by Bongaarts and Feeney (1998) as a refine- 
Table 3: Estimates of the postponement effect for various cohorts in Italy, Spain and Bulgaria. This postponement effect reflects the relative decrease in individual's completed fertility that is associated with a one year delay in the age at first birth

\begin{tabular}{lcccc}
\hline \hline Country & Cohorts & & \\
\hline Italy & $1923-1935$ & $1935-1945$ & $1946-1951$ & $1952-1958$ \\
Postponement effect & $0.0373^{* *}$ & $0.0420^{* *}$ & $0.0480^{* *}$ & $0.0294^{* *}$ \\
& $(0.002)$ & $(0.0018)$ & $(0.0046)$ & $(0.0037)$ \\
Spain & & $1945-1951$ & $1952-1958$ \\
Postponement effect & & $0.0511^{* *}$ & $0.0382^{* *}$ \\
& & $(0.0061)$ & $(0.0041)$ \\
Bulgaria & & $1949-1955$ & $1956-1960$ \\
Postponement effect & & $0.0278^{* *}$ & $0.0266^{* *}$ \\
& & $(0.006)$ & $(0.00515)$ \\
Czech R. & & $1952-1955$ & $1956-1959$ \\
Postponement effect & & $0.0351^{* *}$ & $0.0346^{* *}$ \\
& & $(0.0081)$ & $(0.0070)$ \\
Hungary & & $1952-1954$ & \\
Postponement effect & & $0.0289^{* *}$ & \\
& & $(0.0049)$ & \\
Sweden & 1949 & 1954 \\
Postponement effect & & $0.0215^{* *}$ & $0.0160^{* *}$ \\
& & $(0.0042)$ & $(0.0042)$ \\
\hline \hline
\end{tabular}

Notes: All estimates are based on women who experience their first birth prior to age 32. Analyses include cohort dummies that capture trends in cohort fertility. Standard errors are in parentheses. $p$-values: ${ }^{+} p<0.10{ }^{*} p<0.05 ;^{* *} p<0.01$. Sources: Italy: ISTAT Survey 1983 (Women, only up to 9 births up to age 38) for Cohorts 1923-1945; FFS 1995-96 (Women, weighted, only up to 9 births up to age 38), Cohorts after 1946. Spain: FFS 1995-96 (Women, weighted, only up to 9 births up to age 38). Bulgaria: FFS 1997-98 (Women, weighted, only up to 6 births up to age 38). Czech R.: FFS 1997 (Women, weighted, only up to 5 births up to age 38). Hungary: FFS 1992-93 (Women, only up to 9 births up to age 38). Sweden: FFS 1992-93 (Women, only up to 7 births up to age 38 ) 
ment of the demographic translation methods used by Ryder (1980) or Hobcraft (1996). Their idea was to obtain a counter-factual measure of the total fertility that reflects the TFR that would have been observed in the absence of fertility postponement. This requires adjusting the observed TFR by the proportion of births that are not observed in a given calendar year due to the delay of childbearing. ${ }^{11}$ As indicated earlier, there are two potential problems in this approach (see also van Imhoff 2001; van Imhoff and Keilman 2000). First, the adjustment of the total fertility rate assumes that all women postpone order- $i$ births by the same amount within a calendar year. Empirically this is not necessarily the case. Kohler and Philipov (2001) show that the formula can be generalized to virtually any kind of period-age interactions, and they develop the appropriate formulas to include variance effects in the adjustment of the TFR. Second, the adjustment of the total fertility rate is based on order- and age-specific fertility rates that represent rates of the second kind. These rates are obtained by dividing the number of births of a given parity to women of age $a$ by the number of all women of age $a$ irrespective of parity. It is easily seen that these frequencies are affected by the parity composition of the population of women. This is not desirable since the parity composition of the population reflects past fertility behavior. Our goal, however, is to obtain a pure measure of period fertility that is free of compositional effects and invariant with respect to past fertility changes that occurred prior to the period of interest. Additional distortions due to the use of rates of the second kind occurs because changes in the parity distribution also affect the inference of tempo-changes, and these distortions can lead to an inappropriate separation of tempo and quantum (for a simulation and discussion of these distortions see Kohler and Ortega 2001a).

In order to overcome these problems, we apply the refined adjustment procedure proposed by Kohler and Ortega (2001b) (see also Ortega and Kohler 2001). The basic idea of the Kohler-Ortega approach is based on the following steps: (a) the use of age- and parity-specific childbearing intensities (or rates of the first kind) that are not subject to compositional distortions; (b) the application of the Kohler and Philipov framework, which is a generalization of the Bongaarts-Feeney adjustment, to these childbearing intensities in order to adjust for tempo-distortions; $(c)$ the calculation of tempo and parity composition adjusted measures, such as the index of total fertility and period parity progression ratios, from tempo-adjusted childbearing intensities; $(d)$ the calculation of completed fertility for actual cohorts under alternative scenarios about the future fertility postponement. In particular, we implement two sets of projections for cohorts who are at the beginning of their childbearing years, i.e., at age 15: a postponement stops scenario that is based on the last period's tempo-adjusted childbearing intensities, and a postponement continues scenario that combines these adjusted intensities with a continuation of postponement to future periods, where the future pace of postponement equals the pace observed in the last calendar year. ${ }^{12}$

The distinction between these two scenarios is important due to the postponementquantum interactions indicated above. In the case of the CEE countries, for instance, even a relatively rapid increase in the mean age at first birth of 0.2 years per annum can prevail for up to 30 years until the gap to the currently observed mean age at first birth 
in some Western European countries is closed. In the case of Southern Europe probably postponement will have to start diminishing over time, but it can still go on for some years, especially when it is accompanied with a concentration in the ages of childbirth into a narrow age-interval (see also Section 6). The impact of this potential ongoing delay in childbearing can be revealed - at least to a first approximation - by our postponement continues scenario. In particular, it can reflect the extent to which postponement-quantum interactions under a continued delay of childbearing reduce cohort fertility and the progression probabilities to higher parities.

The data requirements for the above calculations are more severe than those for the calculation of the Bongaarts and Feeney adjusted TFR. In particular, both births and the female population in each calendar year need to be disaggregated by parity and age. We have obtained these data for Italy, Spain, Bulgaria, the Czech Republic and Hungary, and we are therefore able to apply the Kohler-Ortega approach to several important lowest-low fertility countries with different socioeconomic backgrounds. For simplicity we concentrate on the parities 1-4 and ignore births of higher order. ${ }^{13,14}$

Table 4 reports the adjusted total fertility rate (Bongaarts and Feeney 1998) and the measures obtained from the application of the Kohler and Ortega approach. The calculations are averaged across two three-year periods in the early to mid 1980s and mid to late 1990s, and they cover the most recent 15 year time-span for which data are available. ${ }^{15}$ The observed TFR for first births in column one suggests a substantial decline in first-birth fertility, ranging from 16\% (Italy) to $42 \%$ (Czech Republic), during the fifteen years of observation. The adjusted TFR for order one in the 1990s is substantially higher than the observed TFR in the 1990s, and the difference is between 16\% (Bulgaria) to $45 \%$ (Czech Republic). Moreover, the adjusted TFR declined substantially less than the observed TFR between the mid 1980s and late 1990s. These findings suggest that tempo-distortions are of central relevance for depressing fertility at order one, and they also suggest that the quantum of first-birth fertility has declined substantially less than suggested by the observed $\mathrm{TFR}_{1} \cdot{ }^{16}$

In order to avoid the compositional-distortions that potentially affect these conclusions based on the adjusted TFR, we also report the measures suggested by Kohler and Ortega. The third and fourth column in Table 4 reflect the 'lifetime birth probability of at least one child', i.e., the probability that a woman experiences at least one birth. These probabilities are calculated from the observed period childbearing intensities (column 3), and also from the tempo-adjusted childbearing intensities (column 4).

The lifetime birth probabilities in column 3, which are not adjusted for tempo distortions, suggest a period-fertility that implies a probability of at least one child of .73-.83 in the Southern European and of .76-.96 in the Central/Eastern European lowest-low fertility countries. The important observation in column 3 is that the lifetime birth probabilities exceeds the $\mathrm{TFR}_{1}$ by $1-11 \%$ in the 1980 s and $19-45 \%$ in the $1990 \mathrm{~s}$. It also declined substantially less than the observed $\mathrm{TFR}_{1}$. In particular, the decline in the first-birth probabilities ranges only between $10-11 \%$ in Italy and Spain, and $11-16 \%$ in the CEE countries. This observation therefore suggests that the rapid and substantial decline of the total fertility rate for first births is not only driven by tempo effects, but also in 
Table 4: Demographic analysis of lowest-low fertility for Italy, Spain, Bulgaria, the Czech Republic and Hungary

\begin{tabular}{|c|c|c|c|c|c|c|c|c|c|}
\hline Column & $\begin{array}{c}\text { (1) } \\
\text { TFR, } \\
\text { parity } 1\end{array}$ & $\begin{array}{c}(2) \\
\text { Adjust. } \\
\text { TFR, } \\
\text { parity } 1\end{array}$ & $\begin{array}{c}(3) \\
\text { Lifetime } \\
\text { birth } \\
\text { prob., } \\
\text { parity } 1\end{array}$ & $\begin{array}{c}(4) \\
\text { Lifetime } \\
\text { birth } \\
\text { prob., } \\
\text { parity } 1 \\
\text { tempo } \\
\text { adjust. }\end{array}$ & $\begin{array}{c}5) \\
\text { TFR } \\
\text { (parit. } \\
1-4)\end{array}$ & $\begin{array}{c}\text { (6) } \\
\text { adj. } \\
\text { TFR } \\
\text { (parit. } \\
1-4)\end{array}$ & $\begin{array}{c}(7) \\
\text { Index of } \\
\text { complet. } \\
\text { fertility, } \\
\text { observ. } \\
\text { intens. }\end{array}$ & $\begin{array}{c}(8) \\
\text { Index of } \\
\text { complet. } \\
\text { fertility, } \\
\text { tempo } \\
\text { adjust., } \\
\text { postp't } \\
\text { stops }\end{array}$ & $\begin{array}{c}(9) \\
\text { Index of } \\
\text { completed } \\
\text { fertility, } \\
\text { tempo } \\
\text { adjust., } \\
\text { postp't } \\
\text { contin. }\end{array}$ \\
\hline \multicolumn{10}{|l|}{ Italy } \\
\hline 1980-82 & 0.73 & 0.84 & 0.82 & 0.86 & 1.55 & 1.76 & 1.57 & 1.68 & 1.58 \\
\hline 1994-96 & 0.61 & 0.80 & 0.73 & 0.81 & 1.19 & 1.52 & 1.23 & 1.43 & 1.36 \\
\hline \multicolumn{10}{|l|}{ Spain } \\
\hline 1981-83 & 0.79 & 0.92 & 0.83 & 0.85 & 1.90 & 2.16 & 2.00 & 2.00 & 1.88 \\
\hline 1996-98 & 0.58 & 0.72 & 0.75 & 0.85 & 1.15 & 1.47 & 1.35 & 1.69 & 1.52 \\
\hline \multicolumn{10}{|l|}{ Bulgaria } \\
\hline 1982-84 & 0.96 & 0.96 & 0.96 & 0.98 & 1.97 & 2.00 & 1.90 & 1.95 & 1.92 \\
\hline 1997-99 & 0.65 & 0.76 & 0.86 & 0.87 & 1.12 & 1.31 & 1.28 & 1.26 & 1.26 \\
\hline \multicolumn{10}{|l|}{ Czech R. } \\
\hline 1982-84 & 0.90 & 0.89 & 0.91 & 0.92 & 1.98 & 1.99 & 1.93 & 1.95 & 1.94 \\
\hline 1997-99 & 0.53 & 0.76 & 0.76 & 0.87 & 1.13 & 1.63 & 1.27 & 1.48 & 1.31 \\
\hline \multicolumn{10}{|l|}{ Hungary } \\
\hline 1982-84 & 0.85 & 0.92 & 0.89 & 0.92 & 1.72 & 1.88 & 1.71 & 1.82 & 1.78 \\
\hline 1997-99 & 0.57 & 0.79 & 0.76 & 0.88 & 1.27 & 1.62 & 1.32 & 1.57 & 1.35 \\
\hline
\end{tabular}

important manners by shifts in the population parity distribution: even when ignoring tempo-distortions, first-birth fertility declined substantially less than the observed TFR, and this finding becomes visible once the shifts in the parity distribution of the population are accounted for.

These birth probabilities obtained from observed childbearing intensities, however, are still subject to tempo distortions. In column 4 we therefore report the respective calculations obtained from tempo-adjusted childbearing intensities. As expected, the adjustment for tempo-distortions leads to higher first-birth probabilities. However, the assessment about the extent of tempo distortions is substantially diminished. The tempo-adjusted first birth probabilities in the 1990s exceed the probabilities obtained from the observed data by only $10-13 \%$ in Italy and Spain, by $1 \%$ in Bulgaria, and $13-15 \%$ in Hungary and the Czech Republic. These differences are substantially less than the differences between the observed and adjusted $\mathrm{TFR}_{1}$. While tempo distortions and the postponement of parenthood are clearly an important factor in the decline of first-birth childbearing in the 1980-90s, our analyses of lifetime birth probabilities suggest that the relevance of these tempo distortions is exaggerated by the comparison of the TFR with the adjusted TFR.

A further and more substantially relevant finding of our analyses in Table 4 is that the lowest-low fertility patterns observed during the late 1990s in Italy, Spain, Bulgaria, the Czech Republic or Hungary do not imply particularly high levels of childlessness. Once tempo-distortions are removed, our calculations suggest that a cohort experiencing the fertility pattern observed during the late 1990s would attain a childlessness of $13-$ 
19\%. These levels are quite modest compared to the childlessness observed in some other countries, as for instance Germany, where more than one third of the women in the 1965 cohort are expected to remain childless (Dorbritz and Gärtner 1999).

Despite the only moderate declines in the level of first-birth childbearing suggested by the measures in Table 4, it is undisputed that there have been important declines in the level of childbearing in lowest-low fertility countries. These declines, however, are concentrated on higher parities. In columns 5 and 6 of Table 4 we therefore combine parities 1-4 and report both the observed and adjusted TFR. Similar to our earlier discussion, the observed total fertility rate has declined substantially during the decade investigated in Table 4, and the adjustment of the TFR contributes a considerable part of this decline to tempo distortions (a possible exception is Bulgaria, where the postponement of fertility has been quite modest during the late 1990s). In order to avoid compositional distortions, we also compute the index of completed fertility, which reflects the completed fertility of a cohort that experiences the childbearing intensities observed in a given period (the index of completed fertility also equals the TFR if the parity distribution of the population is in equilibrium, but the two measures can differ substantially when the population is out of equilibrium).

In column 7, we use the observed childbearing intensities to calculate an index that is comparable to the observed total fertility rate. In the early to mid 1980s this index of fertility is approximately equal to the TFR, reflecting the fact that the population has not substantially deviated from its equilibrium parity distribution. During the 1990s this index declines to a level of about 1.23-1.35 in all countries. This decline is somewhat less than that of the TFR, and the difference is due to compositional distortions of the total fertility rate.

In addition to these calculations based on the observed intensities, we report analyses based on adjusted childbearing intensities in order to avoid tempo-distortions (column 8 and 9). For this tempo-adjusted fertility index we make two different assumptions about the postponement of fertility during the life-course of a cohort. In the postponement stops scenario the delay of childbearing comes to a halt in 1999 (or for Italy and Spain in the respective last year for which data are available), and the age-pattern of fertility is constant afterwards. We contrast these calculations with a postponement continues scenario in which a cohort at the beginning of its childbearing years experiences both the quantum and pace of fertility postponement that prevailed during the late 1990s.

The postponement stops scenario (column 8) in Italy and Spain reveals a somewhat higher index of fertility than the observed data (except for Spain in the early 1980s, where both are equal), and the difference between the observed and adjusted index is widening during the 1990s due to a more rapid postponement. If the postponement had come to a halt in the mid to late 1990s, therefore, a cohort experiencing the level of fertility during these years would have between 1.4-1.7 children on average. This fertility level is between .24 to .54 children higher than the level of the period TFR, and it represents only a decline of about $15 \%$ as compared to similar calculations for the early 1980s. The situation in Hungary and the Czech Republic is comparable to the Southern European situation in terms of the index of completed fertility, with the primary difference that these countries 
started at a higher fertility level in the initial period. The exception is Bulgaria, where the tempo-adjusted index of completed fertility declined considerably more due to the absence of a rapid fertility postponement in the late 1990s.

Especially in CEE countries such as Hungary and the Czech Republic it seems unlikely that the delay in childbearing comes to a halt in the near future, and even in Italy and Spain we expect some continuation of the postponement. The implications of such an ongoing delay of childbearing are captured in the postponement continues scenario. In all countries with a delay in childbearing in the late 1990s, i.e., all countries in Table 4 except Bulgaria, the index of fertility in the postponement continues scenario is lower, sometimes even substantially lower, than the index obtained in the postponement stops scenario. Therefore, if the postponement continues, the discussion in the previous paragraph may have been too optimistic in terms of the cohort fertility that is implied by the lowest-low period fertility pattern in the late 1990s. For the Eastern European countries in Table 4, the cohort fertility declines to about 1.3 in the postponement continues scenario, which is $14 \%$ below the level in the postponement stops scenario. The difference is $5 \%$ in Italy and $10 \%$ in Spain.

The large difference in index of completed fertility between these two postponement scenarios is due to the different pace of postponement across parities. Due to this asymmetry, a continuation of the delay in childbearing implies a reduction of higher parity births because the exposure to these births is shifted towards older ages at which the probability of progressing to another child is declining. These postponement-quantum interactions are particularly relevant in countries where $(a)$ the delay of childbearing is likely to continue, and $(b)$ socioeconomic conditions, norms, institutional determinants of childbearing, or medical possibilities for late childbearing hinder the progression to second and higher parity children at advanced childbearing ages. The CEE countries clearly fall into this category, and a continuation of the postponement is thus likely to further depress cohort fertility.

In summary, our results in Table 4 suggest that decline in the quantum of first birth has not been a primary driving force in the emergence of lowest-low fertility in the Southern, Central and Eastern European countries that are included in Table 4. While this basic conclusion is similar to the results suggested by the adjusted $\mathrm{TFR}_{1}$, our analyses suggest a different relevance of demographic determinants: tempo-distortions due to the postponement of parenthood have been less important than suggested by the $\mathrm{TFR}_{1}$ and its adjustment, and shifts in the parity composition of the population - that are not included in TFR-based investigations - have importantly contributed in addition to the delay in childbearing. In addition, if postponement stops and the level of fertility stabilizes at its level in the mid- to late 1990s, our calculations in Table 4 suggest a completed fertility for cohorts currently at the beginning of their childbearing years between 1.3 and 1.7 children. If the postponement continues, however, completed fertility will be less due to postponement-quantum interactions. In particular, our calculations suggest that longterm cohort fertility will be close to 1.3 children in Bulgaria, Hungary and the Czech Republic, and it will be between 1.4 and 1.5 children per woman in Italy and Spain.

Lowest-low fertility therefore emerges due to $(a)$ a low quantum of fertility that is 
substantially below replacement level, and (b) tempo- and distributional distortions that depress the observed period fertility measures. The postponement of fertility and the recent and rapid decline of fertility at parity two and higher are the primary determinants of these distortions.

\section{Towards a theory of lowest-low fertility}

In this section, we explore the socioeconomic conditions and individual-level determinants that underlie the demographic patterns identified in the previous section. The basic starting point of our theoretical analyses is the observation that fertility is a dynamic process over the life-course. Children are generally born one at a time, and individuals have considerable control in determining the timing of these events. Due to the widespread availability of reliable contraception in most lowest-low fertility countries, individuals are particularly effective in determining the onset of their exposure to the 'risk' of conception. ${ }^{17}$ An individual's control about conception and successful pregnancy outcomes is somewhat less since these aspects depend on several additional factors that are non-volitional.

In lowest-low fertility countries we can therefore assume that births are looked for or, at least, not intentionally avoided. In such a context, there are different reasons why individuals may not have an extra child for the moment: one may plan to have a child at a later time, or one may plan not to have a child at all, or one might not have a clear idea about these future plans. ${ }^{18}$ It is important that this decision to postpone childbearing can be revised afterwards. There is no irreversible commitment associated with plans to delay fertility, at least within the biological and medical limits that determine the ages of childbearing. This flexibility is in sharp contrast to the transition into parenthood, which is generally irreversible once a child is born.

This asymmetry between the irreversibility of childbirth and the reversibility of future plans about the timing of childbirth provides an incentive to postpone the decision of having children. A postponement can reduce the uncertainty about the costs and benefits of children, and also the uncertainty associated with the economic situation and the stability of partnerships in early adulthood. The potential of young adults to adjust the timing of their fertility is facilitated by the diverging plasticity of quantum and timing decisions. On one hand, choices about the number of children in lowest-low fertility countries are increasingly restricted between childlessness as compared to one or two children. On the other hand, the timing of fertility is relatively plastic. The desired onset of childbearing can range over almost two decades in the life-span from the late teenage years to the mid and late thirties (potentially also later). The timing of fertility in lowest-low fertility countries is therefore likely to be sensitive to changes in the socioeconomic conditions, especially at low parities. 


\subsection{The socioeconomic background of delayed childbearing in lowest-low fertility countries}

The socioeconomic context of decisions about timing of parenthood varies substantially across lowest-low fertility countries. In particular, there is a striking difference between Southern and Central/Eastern European countries. In Southern European countries, per capita income levels are at medium to high levels with steady growth, and these countries have also experienced low inflation (see Table 5). At the same time, the entry into the labor market for young adults is extremely difficult (Table 6). The three lowest-low fertility countries in Southern Europe have the highest youth unemployment rates in the European Union in 1999, and this situation has been essentially unchanged since 1989. Unemployment rates are also higher for females than for males, in contrast to Northern European countries. The link between unemployment and low fertility is also supported by the observation that the only Southern European country with relatively high fertility is Portugal, with considerably lower unemployment rates than its Mediterranean counterparts.

The chronic high unemployment situation in Southern Europe has discouraged youth from entering the labor market, and it has deteriorated working conditions to sometimes precarious situations with mostly low-paid temporary jobs. In addition, there is a crowding-out process in which more educated young people are displacing less educated people from their traditional positions (Dolado et al. 2000a,b). The labor market uncertainty and poor economic prospects in early adulthood also facilitate the commonly observed behavior of prolonging the stay in the parents' household until relatively late ages. In both Italy and Spain, for instance, the successful entry into the labor force tends to accelerate household and union formation (Billari et al. forthcoming). ${ }^{19}$

There is also considerable heterogeneity in the determinants of low fertility and postponement among Eastern Europe countries and former Soviet Republics. While all of these countries share the common experience of the transition from a planned to a market economy, the success of this transition and the economic hardship during the transformation have varied considerably. Some of these tremendous differences in income levels and economic outcome during the transition period are documented in Table $5 .{ }^{20}$ Most of the countries, particularly those in the former Soviet Union, have experienced a decline in output over the transition period. Many countries have also experienced a substantial surge in inflationary pressures during the economic crisis. This is especially the case in the former Soviet Union, and countries such as Bulgaria or Romania.

The indicators of economic stress in Table 5 reflect only partially the enormous uncertainty of individuals about their economic situation and overall well-being during the 1990s. Across all transition countries, income levels have been very volatile, and the median income fluctuated from year to year by as much as 25 per cent (Forster and Toth 1997; Lokshin and Ravallion 2000; Luttmer 2001). Similarly, labor turnover has been very frequent and lead to common spells of unemployment. For instance, 57 per cent of Russian women during 1994-1998 were very concerned about the possibility of not being able to provide themselves with the bare essentials in the following year (Kohlmann and Zuev 
Table 5: Economic indicators for lowest-low fertility countries

\begin{tabular}{|c|c|c|c|c|c|}
\hline & $\begin{array}{c}\text { GNI } \\
\text { per } \\
\text { capita } \\
\mathbf{1 9 9 9} \\
(\mathrm{Th} . \mathrm{US} \$)\end{array}$ & $\begin{array}{c}\text { GDP } \\
\text { average } \\
\text { growth } \\
\text { 1990-99 }\end{array}$ & $\begin{array}{c}\text { GDP } \\
\text { growth } \\
1999\end{array}$ & $\begin{array}{c}\text { Average } \\
\text { inflation } \\
1990-99\end{array}$ & $\begin{array}{c}\text { Personal } \\
\text { Computers } \\
\text { per 1000 } \\
\text { people } \\
1999\end{array}$ \\
\hline Greece & 12.1 & 2.2 & 3.4 & 6.2 & 60.2 \\
\hline Italy & 20.2 & 1.4 & 1.4 & 3.4 & 191.8 \\
\hline Spain & 14.8 & 2.2 & 3.7 & 3.1 & 119.4 \\
\hline Bulgaria & 1.4 & -2.7 & 2.4 & 116.5 & 26.6 \\
\hline Czech R & 5.0 & 0.8 & -0.2 & 7.7 & 107.2 \\
\hline Estonia & 3.4 & -1.3 & -1.1 & 15.5 & 135.2 \\
\hline Hungary & 4.6 & 1.0 & 4.5 & 17.4 & 74.7 \\
\hline Latvia & 2.4 & -4.8 & 0.1 & 9.2 & 82.0 \\
\hline Romania & 1.5 & -0.8 & -3.2 & 61.4 & 26.8 \\
\hline Slovenia & 10.0 & 2.4 & 4.9 & 9.9 & 251.4 \\
\hline Armenia & 0.5 & -3.2 & 3.3 & 32.5 & 5.7 \\
\hline Belarus & 2.6 & -3.0 & 3.4 & 169.6 & \\
\hline Georgia & 0.6 & -14.9 & 3.3 & 11.6 & \\
\hline Russia & 2.3 & -6.1 & 3.2 & 52.0 & 37.4 \\
\hline Ukraine & 0.8 & -10.7 & -0.4 & 69.8 & 15.8 \\
\hline Croatia & 4.5 & 0.2 & -0.3 & 5.8 & 67.0 \\
\hline Lithuania & 2.6 & -4.0 & -4.2 & 16.6 & 59.5 \\
\hline Poland & 4.1 & 4.5 & 4.1 & 15.8 & 62.0 \\
\hline Slovakia & 3.8 & 1.8 & 1.9 & 6.5 & 109.3 \\
\hline Austria & 25.4 & 1.9 & 2.1 & 1.3 & 256.8 \\
\hline Germany & 25.6 & 1.3 & 1.5 & 1.2 & 297.0 \\
\hline Japan & 32.0 & 1.3 & 0.2 & -0.5 & 286.9 \\
\hline Korea & 8.5 & 5.7 & 10.7 & 3.5 & 181.8 \\
\hline
\end{tabular}


Table 6: Youth unemployment rates (under 25) in Southern Europe

\begin{tabular}{lcccc}
\hline \hline Country & Women 1999 & Women 1989 & Men 1999 & Men 1989 \\
\hline Italy & 38.3 & 38.5 & 28.6 & 25.9 \\
Greece & 39.3 & 34.0 & 21.4 & 17.0 \\
Spain & 37.3 & 42.6 & 21.7 & 24.4 \\
Portugal & 11.1 & 15.8 & 7.5 & 8.3 \\
EU (15) & 19.2 & 19.6 & 16.7 & 14.4 \\
\hline \hline Source: OECD, Employment Statistics (available at http://www.oecd.org)
\end{tabular}

2001).

The structure of wages and employment has also been transformed in Eastern Europe. The returns to human capital have considerably increased as compared to the pretransition period, and young cohorts can expect reward levels for skills that approach - or are comparable to - the returns in western European countries. In contrast, there has been a decline in the returns to experience for low educated people. As a result, poverty is particularly common among the low educated and those having more than two children. ${ }^{21}$

\subsection{Postponement as a rational response to socioeconomic incentives}

Based on the above sketch of the socioeconomic background, we can investigate the individual-level determinants of delayed childbearing in lowest-low fertility countries. Certain elements are common to all lowest-low fertility countries. These commonalities include high levels of economic uncertainty in early adulthood. This uncertainty provides an incentive to delay decisions that imply long-term commitments, such as children, and it provides an incentive to invest in education and human capital.

In the Southern European countries, the uncertainty is basically due to youth unemployment and/or job instability. High unemployment risks simultaneously lower the opportunity costs of pursuing higher education and create incentives for education due to the increased employment opportunities. Higher education has thus become the primary pathway for individuals to increase their chances of finding a stable job with a sufficient wage (Lassibille et al. 2001; Sá and Portela 1999). In the CEE countries, the uncertainty is due to the overall economic insecurity and hardship caused by the transition. Moreover, the economic transition has increased the returns to education. The combination of these factors has rendered human capital investments very attractive since these investments provide insurance against poverty and enable access to more stable employment with relatively high salaries. The main problem in attaining education faced by individuals in Eastern Europe is that the opportunity costs may be too high in some of the poorest countries. Parents may have problems financing higher education of their children since they are also affected by the transition, and credit constraints may preclude access to loans in order to cover tuition and consumption during studies.

Table 7 shows the university enrollment ratios in the different countries in 1996 as compared to 1989. In particular, the table reflects the drastic increase in higher educa- 
Table 7: Educational indicators for lowest-low fertility countries

\begin{tabular}{|c|c|c|c|c|c|c|}
\hline \multirow[b]{3}{*}{ Country } & \multirow{2}{*}{\multicolumn{3}{|c|}{$\begin{array}{l}\text { Gross University } \\
\text { Women }\end{array}$}} & \multicolumn{3}{|c|}{ Enrollment Ratios } \\
\hline & & & & & & \\
\hline & 1989 & 1996 & & 1989 & 1996 & \\
\hline Greece & 24.5 & 46.3 & & 23.9 & 47.4 & \\
\hline Italy & 29.1 & 51.6 & & 30.3 & 42.3 & \\
\hline Spain & 33.8 & 55.6 & & 36.3 & 47.4 & \\
\hline Bulgaria & 28.2 & 51.6 & & 24.4 & 31.2 & \\
\hline Czech R & 13.9 & 23.3 & & 17.7 & 23.8 & \\
\hline Estonia & 26.5 & 45.7 & & 25.7 & 38.1 & \\
\hline Hungary & 14.9 & 25.7 & & 13.7 & 21.5 & \\
\hline Latvia & 29.0 & 39.6 & & 20.4 & 27.0 & \\
\hline Romania & 8.4 & 24.3 & & 8.6 & 20.8 & \\
\hline Slovenia & 27.8 & 41.3 & & 22.3 & 31.1 & \\
\hline Armenia & 23.8 & 14.0 & (both) & & 10.5 & \\
\hline Belarus & 50.3 & 49.1 & & 45.5 & 38.6 & \\
\hline Georgia & 39.8 & 44.4 & & 33.8 & 39.7 & 1990 \\
\hline Russia & 58.9 & 42.8 & & 48.4 & 48.5 & 1994 \\
\hline Ukraine & 45.8 & 41.7 & & & & 1995, Both \\
\hline Croatia & 22.7 & 29.1 & & 22.7 & 26.8 & \\
\hline Lithuania & 39.9 & 37.8 & & 29.8 & 25.3 & \\
\hline Poland & 24.4 & 28.5 & & 16.5 & 21.0 & \\
\hline Slovakia & 15.8 & 22.6 & & 16.4 & 21.6 & 1992 \\
\hline Austria & 28.9 & 48.8 & & 33.1 & 47.8 & \\
\hline Germany & 29.9 & 44.4 & & 40.3 & 49.9 & 1991 \\
\hline Japan & 22.9 & 36.5 & & 35.0 & 44.4 & 1994 \\
\hline Korea & 23.7 & 52.4 & & 50.1 & 82.0 & 1997 \\
\hline
\end{tabular}

The gross enrolment ratio is the total enrolment in secondary education, regardless of age, divided by the population of the age group which officially corresponds to secondary schooling. Source: UNESCO, Institute for Statistics (online available at http://www.unesco.org). 
tion in Southern European countries where half of the women pursue university studies in the mid-1990s. Central and Eastern European countries share this general trend towards increased enrollment ratios, particularly for women. Estonia, Slovenia, Latvia and, surprisingly, Bulgaria, have strongly increased their enrollment ratios to levels comparable to western countries. The levels in the Czech Republic, Hungary and Romania have also increased, but since these countries started at much lower levels they are still lagging behind. The only deviations from the trend towards increased higher education are among the former Soviet Republics.

The comparison of the evolution of university enrollment with the mean age at childbearing is very illuminating. The countries with marked increases in higher education tend to be identical to the countries with the most pronounced delays in the mean age at first birth. ${ }^{22}$ This association between delays in childbearing and increases in individuals' human capital investments is consistent with our hypothesis: increasing returns to education induce young adults - and particularly young women - to study for a longer time in the expectation that this improves their ability to cope with the economic uncertainty and to take advantage of the new opportunities created during the transition period. Exceptions to this general pattern seem to be concentrated among countries where the economic situation is worst, and where the coping strategy of higher education and human capital investments is not accessible for important fractions of the population. ${ }^{23}$ In addition to the human-capital motive for delaying childbirth, the very unstable standards of living in Eastern Europe also lead to a strategic postponement in which children - and similar decisions implying long-term commitments - are deferred in the expectation that the uncertainty about the future prospects is reduced over time. ${ }^{24}$

Changes in social policy are an important additional factor in the former socialist countries. In the socialist period many countries had developed a system of incentives that rewards early childbearing, for instance via easier access to housing and paid maternity leave. These incentives resulted in a reduced age at motherhood, especially during the 80s (Frejka 1980; Zakharov and Ivanova 1996). During the 1990s many of these benefit structures have ended, or eroded due inflation, or were modified, and this fact has also contributed to the postponement of motherhood in the last decade.

A further determinant of the 'postponement-low-fertility nexus' is the delay of childbearing in association with investments in housing and durables. This is especially relevant in Italy and Spain, where the interference of childbearing with educational investments has been much reduced due to the delay of parenthood to very late ages. In these countries, the preponderance of own property in the housing market and the restricted rental market induces young people to stay at home with their parents until their financial resources are adequate for paying the mortgage (Duce Tello 1995). ${ }^{25}$ Since this can take several years after entry in the labor market, this process can lead to delays of childbearing substantially beyond the completion of higher education. 


\subsection{Social feedback effects on the timing of fertility}

The previous section has primarily focused on individuals' incentives that render delayed childbearing more advantageous. The discussion of these individual-level determinants of timing decisions, however, is not sufficient to understand the dynamics of fertility postponement in lowest-low fertility populations (and more generally, also in other low fertility populations). In particular, we believe that the analysis of individual's responses to socioeconomic incentives and socioeconomic changes needs to be integrated with a consideration of social interaction and its effect of the dynamics of fertility change.

Social interaction effects have established themselves firmly in recent theories about fertility decline in developing countries or during the European demographic transition (Bongaarts and Watkins 1996; Dasgupta 2000; Entwisle et al. 1996; Kohler 2001; Kohler et al. 2001; Montgomery and Casterline 1996; Watkins 1990). The discussion of these effects is frequently phrased in terms of social learning and social influence (Kohler et al. 2001; Montgomery and Casterline 1996). The former stresses that the uncertainty associated with fertility or contraceptive decisions can be reduced through learning about the experience of friends, neighbors or other network partners. The latter stresses normative influences on fertility-related preferences and attitudes that are exerted through the social environment.

Despite the increasing attention devoted to this issue by demographers, social interaction is not yet routinely integrated in research and theoretical frameworks for fertility in developed countries. This is surprising since social learning and social influence are likely to remain relevant also in industrialized countries. Moreover, the role of social interactions is not restricted to these two mechanisms. In particular, contemporary low and lowest-low fertility contexts provide additional pathways of social interactions that have not been discussed in the demographic literature so far: social feedbacks mediated through the marriage market and feedback effects operating through competition in the labor market.

The presence of social interaction, independent of the specific mechanisms that lead to its relevance for fertility behavior, exerts important influences on the dynamics of the fertility postponement for at least three reasons (Kohler et al. 2000; Montgomery and Casterline 1996): (a) social multiplier effects tend to increase the overall behavioral adjustment resulting from socioeconomic changes, and they can increase the pace and extent of fertility delays in response to socioeconomic changes; $(b)$ social interaction can give rise to multiple equilibria - or multiple demographic regimes - with early and late childbearing, and transitions between these equilibria can lead to rapid and irreversible changes in the timing of fertility; (c) status-quo enforcement can lead to persistent norms and path-dependent fertility developments in situations with strong familial and social ties, and this implication can help to explain the only gradual emergence of 'new' demographic behaviors - such as out-of-wedlock childbearing - in countries like Italy.

Before we turn to these dynamic implications of social interactions, we briefly review the arguments of why social interaction is likely to be an important determinant of fertility change even in developed countries.

Social learning about the optimal timing of fertility: The optimal timing of fertility is a 
highly complicated problem for women or couples, especially in the context of uncertainty and changing socioeconomic environments. ${ }^{26}$ Social learning provides a possibility to simplify and augment decision-making in this context. Childbearing and career experiences of friends are therefore likely to influence women's and couples' decisions about the timing of fertility. For instance, the interaction with others can provide information about questions like "How did classmates, who had their first child relatively early, fare in terms of career and partnership?" and "What is the divergence in social and economic attainment between those who had their children early as compared to those who had them later?" 27

In a population that delays childbearing, social learning from others implies that the experience of friends having children is revealed at an increasingly later age. A women at some given age, say age 25 , therefore faces more uncertainty about the advantages and disadvantages of childbearing in a population that exhibits a late pattern of childbearing as compared to an identical woman in a population with early childbearing. Higher uncertainty in turn implies a further incentive to delay childbearing. In the next section we show that this dependence of an individual's timing decision on the prevailing population pattern through social learning leads to a multiplier effect that reinforces the impact of socioeconomic changes on the timing of fertility.

Social influences on the desired timing of fertility: Normative influences of the social environment on various aspects of entering parenthood and childbearing are a second important mechanism of how social interactions affect fertility decisions. Due to the relatively moderate levels of childlessness and the low progression probabilities to higher parities, the norms pertaining to the age of entering parenthood, the acceptance of outof-wedlock childbearing and female labor force participation are of particular relevance in lowest-low fertility countries.

The importance of such norms on the timing of demographic events has been a central issue in the life-course approach, and there is cumulating empirical evidence about the relevance of norms for the timing of marriage, fertility and the completion of higher education (e.g., Billari and Liefbroer 2001; Billari and Micheli 1999; Heckhausen 1999; Oppenheim Mason 1983; Settersten and Hägestad 1996; White 1998). ${ }^{28}$ Similar to our discussion of social learning, we are interested in these social influences not only because of their direct effect on individual's behavior, but also because of the associated social multiplier effect. This multiplier effect occurs, for instance, because changes in innovative subpopulations in response to new socioeconomic conditions imply an erosion and transformation of the prevailing social norms that affect such behavior. The behavioral change of the innovators thus has an indirect effect on the incentives and normative context of fertility decisions in the population in general, and this indirect effect makes it more likely that others will adopt the new behavior as well. ${ }^{29}$

Social feedbacks mediated through the marriage market: In many lowest-low fertility countries, partnership formation and marriage are inherently connected with the transition into parenthood. This is particularly the case in Italy and Spain, where out-ofwedlock childbearing is still relatively rare, pre-marital cohabitation is not wide-spread, and the trend towards late childbearing is associated with late home-leaving and late union-formation (De Sandre 2000; Delgado and Castro Martín 1998). 
An important demographic implication of the trend towards late union-formation is the induced shift in the composition of potential mates in the marriage market. Research on the determinants of marriage rates has consistently demonstrated that shifts in the composition of available partners influence the timing of union formation, and marriage squeezes caused by rapid changes in cohort sizes can lead to substantial delays in marriage and/or cohabitation (e.g., Fraboni and Billari 2001; Grossard-Shechtman 1985). While the traditional literature on marriage squeezes emphasizes the effect of differential cohort sizes, similar implications are caused by changes in the age-distribution of union formation. In particular, a general delay of partnership formation in the population leads to a social multiplier effect because it increases the probability of finding a partner at later ages, for instance, after finishing more extended education. Moreover, because the marriage market will be 'thicker' and contain more potential mates at any given age, the expected 'quality' of marriageable partners at older ages is also higher in populations with delayed marriage.

A later pattern of union-formation in the population therefore reduces the costs of delaying marriage or cohabitation for individuals: it increases the probability of finding a partner at a later age and it increases the expected 'quality' of the match between the characteristics of oneself and one's partner. ${ }^{30}$ Socioeconomic changes that provide incentives for delayed childbearing, for instance higher returns to female education or technological innovations facilitating fertility control, therefore affect the timing of marriage in a twofold manner: first, via a direct effect on individual's incentives to delay, and second, via an indirect effect through the changes in the pool of marriage partners at later ages caused by an overall later pattern of union formation in the population.

Social feedbacks through competition in the labor market: A final potentially relevant mechanism of social interaction is competition in the labor market that is caused by the presence of high unemployment. In this situation, the labor market can give rise to a social multiplier effect, quite similar to the mechanism operating through the marriage market above (for a related formal model, see Kohler 2001, Chapter 6). In particular, social interaction reinforces the effect of unemployment and economic uncertainty towards delayed childbearing. This social multiplier effect arises because women with children tend to have lower labor supply than women without children, especially in those low and lowest-low fertility countries with inflexible labor markets and insufficient supply of day-care. In this situation, a delay of childbearing in the population increases the level of childlessness among women at the primary ages of entering the labor market. This increased childlessness leads to an increased female labor supply, which in turn increases the competition and unemployment risks during early adulthood. The postponement of fertility caused by unemployment during early adulthood is therefore exacerbated through a feedback process that increases the overall female labor supply in the age groups that are most affected by economic stress. ${ }^{31}$

\subsection{The dynamics of delayed childbearing: postponement transitions}

Considering the above, social interaction mechanisms can improve our understanding of the dynamics of fertility postponement. In particular, we will argue in this section that 
the delay of childbearing follows a postponement transition that shares many characteristics of the fertility transition in Europe or contemporary developing countries: ${ }^{32}$ (1) the postponement transition occurs across a wide range of socioeconomic conditions; (2) once initiated, the population will experience a rapid and persistent delay in the timing of childbearing, and the pace of this postponement transition is only weakly associated with the socioeconomic conditions of countries; (3) it is likely that the transition towards the latefertility regime continues, even if the socioeconomic changes that initiated the transition are reversed.

This notion of a postponement transition is substantiated by Figure 1. In this figure we define the year of onset of the postponement transition as the first in a group of three years during which the mean age at first birth increases by more than .3 years. Within lowest-low fertility countries, this year of onset ranges from 1976 (Italy) to 1994 (Russia, Armenia) (see Table 2). Belarus has not initiated the postponement transition according to our definition. The horizontal axis in Figure 1 plots the years since the onset of the postponement transition, and the vertical axis depicts the change in the mean age at first birth since this onset. In order to avoid a cluttering of the graph, we display some CEE countries with a very recent onset in a sub-graph. In addition we include the Netherlands as a representative Western European country with an early onset of the postponement transition (1972) and a moderately high total fertility rate (1.65 in 1999).

The figure reflects the substantial increases in the mean age at first birth in lowest-low fertility countries that we have emphasized throughout this paper. More importantly, the standardization of the time-scale in this figure reveals several key characteristics that seem to be inherent to the postponement of fertility: $(a)$ the onset of delayed childbearing in lowest-low fertility countries is a break with an earlier regime that is characterized by a relative stability in first-birth timing; $(b)$ once initiated, the postponement transitions in all lowest-low fertility countries is persistent and irreversible, leading to large changes in the mean age at first birth; $(c)$ the broad characteristics of the postponement transition are similar across a wide range of socioeconomic conditions: for instance, the paths for the Netherlands, Italy, Spain, Greece, Slovenia, Hungary, and the Czech Republic - that is, all countries with an onset of the transition up to 1992 - trace each other closely. This similarity occurs despite the fact that these countries represent very different socioeconomic conditions in Europe, including also very different patterns of post-1990 economic crises in Eastern Europe. For countries with an onset of the transition after 1993 it is still very early to make inferences about the path of the postponement transitions, but it seems very likely that they will follow the other lowest-low fertility countries.

The empirical characteristics of postponement transitions in low and lowest-low fertility countries in Figure 1 can be consistently explained by the combination of individual-level incentives for delaying childbearing and the aggregate-level implications of social interactions. Moreover, either aspect alone is likely to be insufficient. In order to demonstrate this interaction of individual incentives and feedback mechanisms caused by social interaction, we elaborate how the above properties of postponement transitions emerge from our theoretical framework. We focus, for simplicity, on the timing of the first child, which is the most pivotal parity in lowest-low fertility countries. 


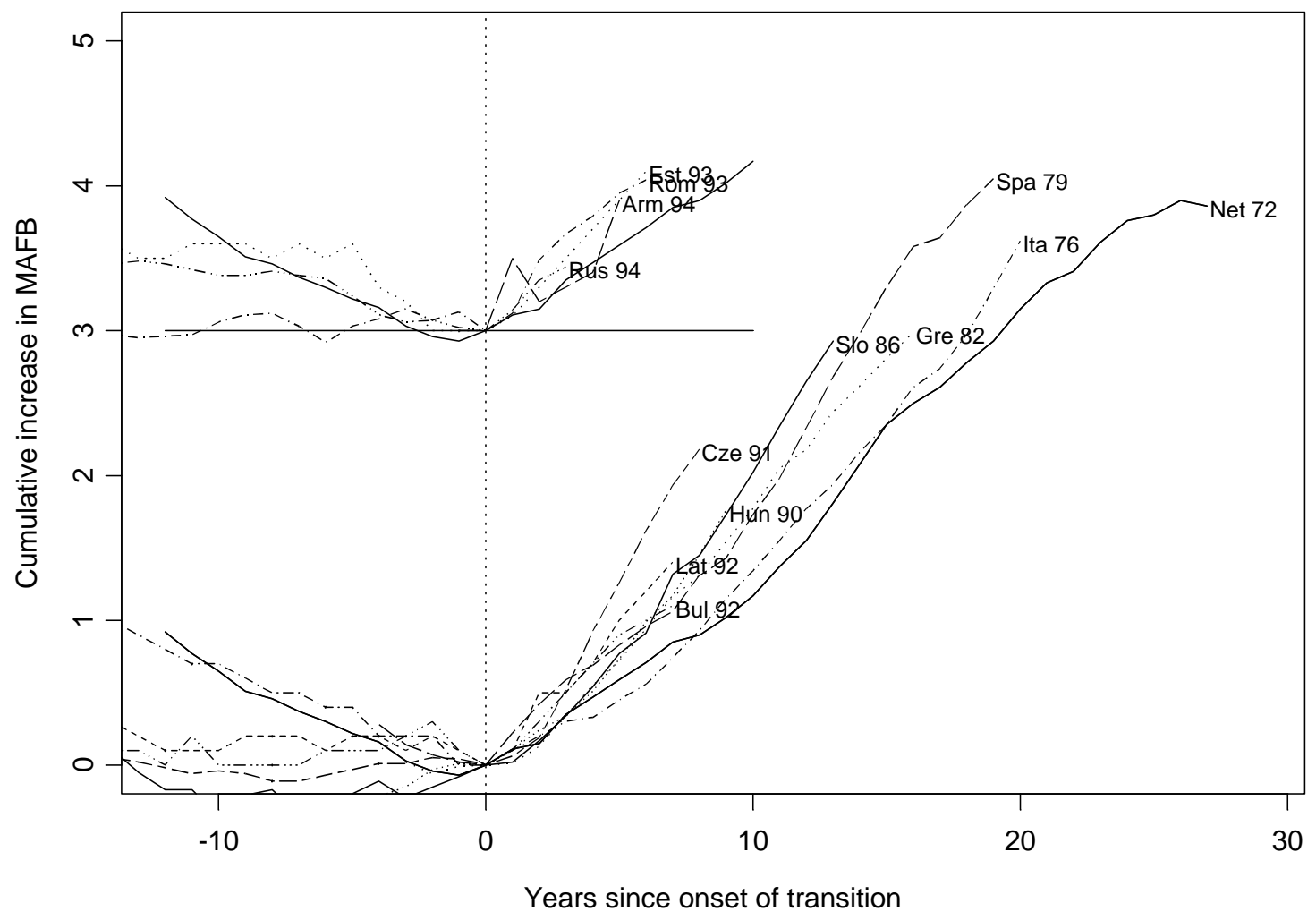

Figure 1: Onset and pace of the postponement transition in lowest-low fertility countries and the Netherlands

Figures 2 and 3 depict two cases of a stylized population in which social interaction effects influence the desired age at first birth. The horizontal axis denotes $\bar{A}$, which is the average age at first birth in the population. We use this measure to reflect the overall agepattern of childbearing in the population. The vertical axis denotes $E A_{i}^{*}$, which denotes the expected value (or average) of the desired timing $A_{i}^{*}$ of the first birth of all women (or couples), indexed by $i$, in the population. On the individual level, this desired timing depends on individual characteristics (e.g., education, familial background or preferences) and on aggregate socioeconomic determinants (e.g., wages, prices of child-care, state support for children). The expectation $E A_{i}^{*}$ then represents the average desired age at first birth that emerges from the aggregation of these - potentially quite heterogeneousindividual desires about the age at first birth.

A novelty in these figures is that social interaction - through the different mechanisms outlined above - implies a dependence of the individually desired timing of childbearing on the prevailing mean age at first birth in the population. In particular, all of the above mechanisms imply that delays in the average birth timing in the population lead to a later individual desired age at first birth. Since all members of the population are affected by these social interaction effects, the individual changes in birth timing lead to a similar 


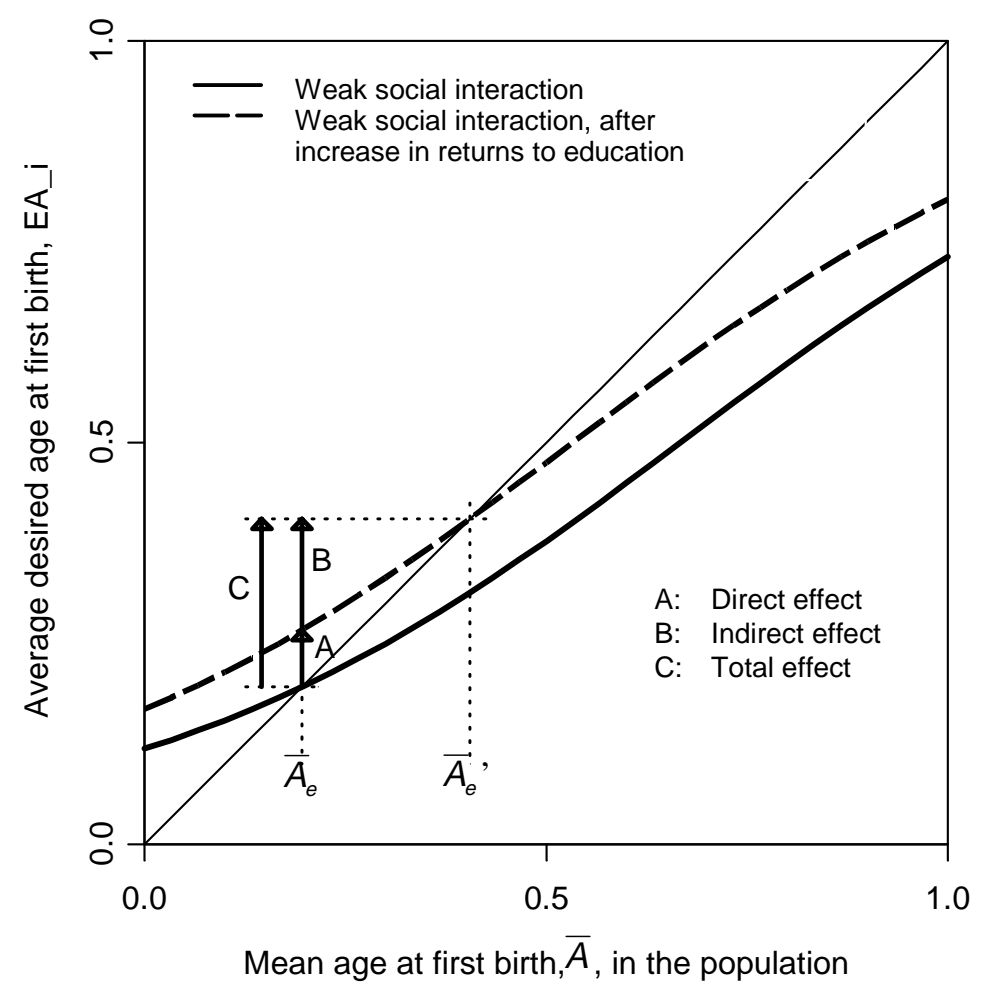

Figure 2: Fertility postponement with weak social interactions and single equilibrium

shift in the expectation $E A_{i}^{*}$. The average desired age at first birth is therefore a function of the age-pattern of fertility in the population, and we write this dependence as $E A_{i}^{*}(\bar{A})$. We do not provide a specific micro-foundation for this dependence beyond our intuitive arguments in the previous section, but ample formal models that reflect the different mechanisms have been developed in the literature and can be transferred analogously to our context of birth timing (for a discussion of this literature, see for instance Kohler 2001).

The two figures reflect the main implications caused by the social interaction effects that help to understand the large, pervasive and rapid changes in birth timing in recent decades. Figure 2 represents a model in which the relation $E A_{i}^{*}(\bar{A})$ is only modestly sloped upward: changes in the age-pattern of childbearing in the population have only small effects on individuals' desired age at first birth. This situation therefore represents weak social interactions. The most important implication is that the solid line in Figure 2 intersects the $45^{\circ}$ line only once at the level $\bar{A}_{e}$. This intersection is an equilibrium to which the birth timing in the population will converge based on the prevailing socioeconomic conditions (like prices, wages, child-care institutions, etc.). If the observed mean age at first birth is to the left of the equilibrium level $\bar{A}_{e}$, then the average individually desired age at first birth will be above the prevailing population mean age at first birth and the 


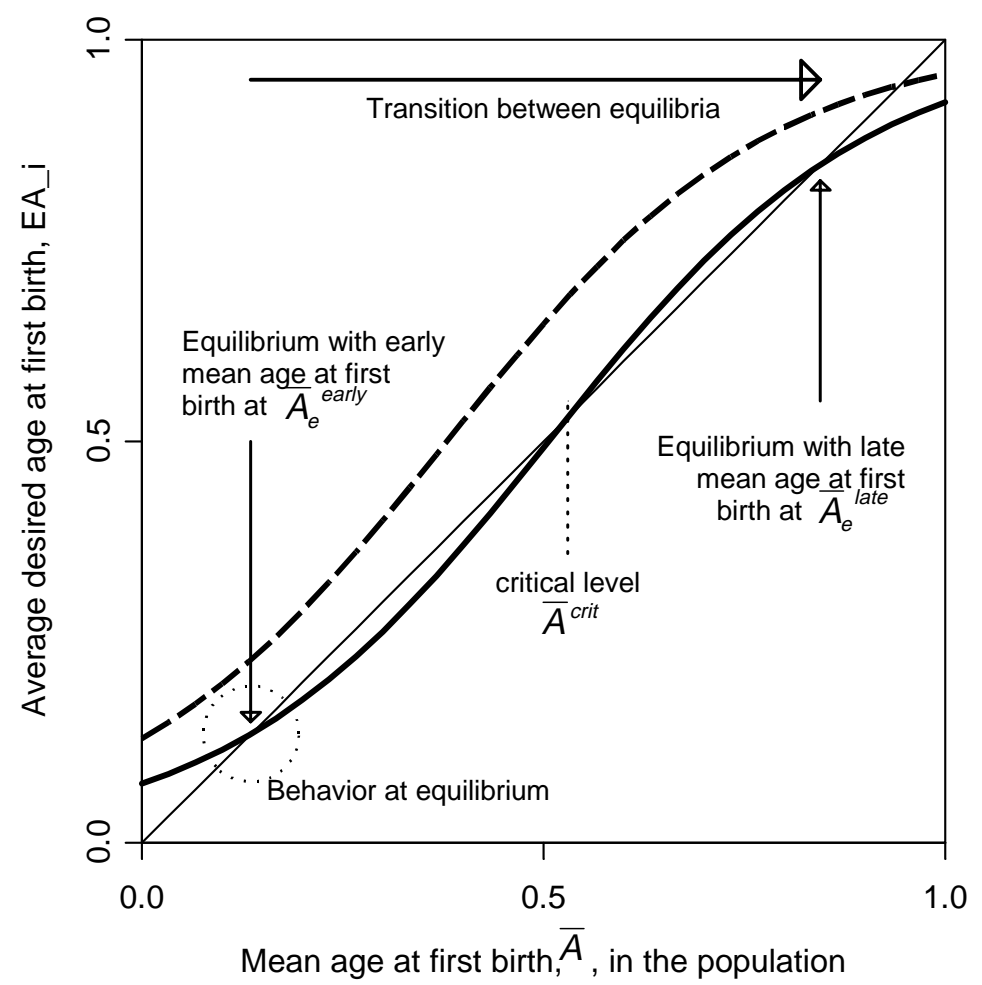

Figure 3: Fertility postponement with strong social interactions and multiple equilibria

population will tend towards the equilibrium level $\bar{A}_{e}$. The same reasoning holds for the case when the population is to the right of the equilibrium level. The equilibrium $\bar{A}_{e}$ will therefore be stable. Homeostatic forces then imply that the mean age at first birth fluctuates around the equilibrium level, or even stabilizes in the absence of perturbations.

But what happens if there is an increase in the returns to female education, or a higher uncertainty in early adulthood, that leads to a delay in the individually desired age at first birth? The direct effect of these new socioeconomic conditions shifts the full line in Figure 2 upward so that it reflects the later childbearing desires of individuals. However, the initial timing of fertility in the population, given by the level $\bar{A}_{e}$, is no longer an equilibrium, and the age-pattern of childbearing will adjust towards the new stable situation in $\bar{A}_{e}^{\prime}$. Therefore, the total shift in the timing of childbearing due to the increase in female educational returns is the difference between the equilibrium levels $\bar{A}_{e}$ and $\bar{A}_{e}^{\prime}$. This overall shift towards delayed childbearing is the sum of the direct effect caused by socioeconomic changes and the indirect effect - or social multiplier effect- due to social interactions.

These social multiplier effects can be quite substantial even if social interaction is only of modest relevance. Relatively small changes in the returns to education or small increases in uncertainty, which in the absence of social interaction would lead to only 
slightly delayed childbearing, can therefore result in relatively large shifts in the timing of fertility. Moreover, it can be shown that the social multiplier effect is stronger the more relevant is social interaction (Kohler et al. 2000). An identical change in educational returns or individuals' employment uncertainty therefore leads to larger shifts in the agepattern of childbearing in societies that are characterized by a greater relevance of social interactions.

The social multiplier effect, however, is not the only relevant implication of social interactions for the dynamics of tempo changes in lowest-low fertility countries. In particular, if social interaction is relatively strong, for instance due to strong normative influences on the timing of fertility or relatively imperfect and inflexible labor markets with high unemployment, then the feedback effect caused by social interactions can lead to multiple equilibria. Figure 3 shows such a situation with an 'early fertility equilibrium', characterized by a relatively young age of entering parenthood, and a 'late fertility equilibrium', where childbearing is initiated at a relatively old age. These two equilibria are stable, and they therefore represent two distinct and self-sustaining demographic regimes with different birth timing: in the absence of substantial socioeconomic changes, the timing of fertility will fluctuate around the young childbearing ages $\bar{A}_{e}^{\text {early }}$ if the population is in the early fertility regime, and the timing of fertility fluctuates around the late childbearing ages $\bar{A}_{e}^{\text {late }}$ if the population is in the late fertility regime. It is important to note that these different equilibrium levels are merely due to social interaction, and two populations facing otherwise similar socioeconomic conditions such as wages or family policies, can exhibit large differences in the timing of fertility. Moreover, transitions between equilibria can lead to substantial, rapid and persistent increases in the mean age at first birth within relatively short periods of time, and these shifts may be associated with relatively modest socioeconomic transformations once the postponement of fertility is initiated.

In a dynamic perspective, a population is likely to begin in the early fertility regime, and as long as mortality is high and/or low fertility is not a rational individual behavior, a late fertility equilibrium may not even exist. The late fertility equilibrium is likely to emerge once the general pre-conditions for below-replacement and low fertility are given. In the multiple equilibria situation, however, the existence of this late-fertility regime does not imply the immediate transition to later childbearing. On the contrary, in the absence of large socioeconomic changes or policy interventions, the population is likely to be 'stuck' in the early fertility regime with little or only modest changes in the timing of childbearing. In the early phase of fertility change, the timing of fertility is therefore likely to be relatively stable, while important changes occur in the quantum of fertility.

Further socioeconomic changes, like increased returns to female education and/or more economic uncertainty during early adulthood, are likely to erode and possibly eliminate the initial early-fertility equilibrium. In the former case, the homeostatic forces keeping the population in the initial regime diminish. Small random events can then lead to an onset of a transition to the late-fertility regime. If the early fertility equilibrium has completely disappeared due to socioeconomic changes - as indicated by the broken line in Figure 3 - the onset of this transition will be deterministic.

Once the transition is initiated, the population will experience a rapid and persistent 
delay in the timing of childbearing that appears to observers as if it is driven by its own momentum. This pattern is consistent with Livi-Bacci's (2001) characterization of the Italian situation as a "postponement syndrome" in which past delays in childbearing provide the primary impetus for an ongoing postponement of fertility. In addition to these persistent and large timing changes, our multiple-equilibria model in Figure 3 also implies that the transition towards the late-fertility regime continues even if the socioeconomic conditions that initiate the transition are reversed. This is the case because the latefertility regime represents a stable equilibrium, and a population will be attracted to this regime - even in the presence of a viable early-fertility equilibrium - as soon as some initial socioeconomic changes have resulted in a delay of childbearing beyond the critical level $\bar{A}^{\text {crit }}$ in Figure 3. For instance, the transition to postponed childbearing is likely to continue even if the economic uncertainty due to unemployment in early adulthood, which is an important determinant of the onset of the transition, disappears and the economic situation of young adults improves. The postponement of childbearing is therefore likely to be persistent, despite the fact that socioeconomic situations that initiate the onset of this transition are only temporary and transient. ${ }^{33}$

The above multiple-equilibria model also provides a framework for understanding the pattern of cross-country divergence during the postponement transition. Countries that are initially homogeneous in their age-pattern of fertility due to the prevalence of a single early-fertility equilibrium can diverge once a late-fertility regime exists. The leading countries will initiate a transition during a period when both the early- and late-fertility equilibrium prevail. The onset of the transition in these cases will be related to temporary and potentially small influences such as temporary economic 'shocks', or policy changes, or ideational factors. ${ }^{34}$ This onset in the forerunners is therefore likely to be path-dependent. Once the initial early-fertility equilibrium has vanished, as shown by the broken line in Figure 3, then the transition towards late childbearing is deterministic, and virtually all countries with comparable socioeconomic conditions will follow a similar transition path.

We believe that many of the socioeconomic changes that erode the early-fertility equilibrium, such as increased returns to human capital investments or the occurrence of uncertainty in early adulthood, are quite pervasive and will gradually affect most developed countries and induce a tendency towards later childbearing. In the very long term, we therefore expect a convergence of countries in the timing of fertility at relatively late ages. ${ }^{35}$ Important differences, however, are likely to occur between countries in the pace of the postponement transition and in the timing of its onset. In particular, social interaction in multiple equilibria situations is likely to be status-quo enforcing (Kohler 2001; Kohler et al. 2000): the more relevant are the feedbacks due to the mechanisms described above, the more persistent will be the initial status quo. The full line in Figure 3 is likely to exhibit a stronger $S$-shape, and the initial equilibrium is likely to be more robust with respect to socioeconomic changes. Once the effect of socioeconomic change is sufficiently strong to eliminate the initial equilibrium despite the presence of a more pronounced $S$ shape, the adjustment towards late childbearing is likely to occur at a faster pace than in countries with weaker social interaction and an earlier onset of the transition to late childbearing. 
In the presence of this multiple equilibria situation, we therefore expect an inverse relation between the pace of the transition towards late childbearing and the onset of the transition: the later the onset, the more rapid the delay in childbearing is. Countries with a late onset of a delay in childbearing are therefore more likely to experience lowest-low fertility due to the presence of large tempo and compositional distortions.

This implication can be investigated on the basis of the postponement transitions in Figure 1. In particular, the Netherlands with its relatively early onset of the transition provides a lower bound to all other country-specific paths. Italy, which initiates its postponement transition just four years afterwards, experienced a more rapid delay of childbearing in the initial 20 years of the transition. Spain, which started its transition in 1979, achieved an even more rapid postponement. Other countries with an even later onset, such as Slovenia, Hungary, Czech Republic, and Latvia are postponing even faster, and Greece only lags behind Spanish postponement in the most recent years. In general, Figure 1 represents a systematic - although not perfect - relation between the year of onset of the postponement transition and the pace of the delay: the later the onset the more rapid the pace during the transitions. Exceptions to this pattern are represented by Bulgaria, which has experienced only modest postponement with a declining pace in recent years, some of the CEE countries (represented in the sub-graph) that entered the postponement transition only recently in the mid-1990s.

\subsection{Determinants of the quantum in lowest-low fertility countries}

The quantum of fertility is a further determinant of lowest-low fertility that needs to be considered in addition to the delay of childbearing and the dynamics of postponement transitions. In particular, lowest-low fertility countries share an institutional setting that implicitly favors a relatively low quantum of fertility (see Section 3.2 for estimates of the cohort fertility associated with currently observed lowest-low TFR levels). For instance, lowest-low fertility countries in Southern Europe, Italy and Spain, provide highly insufficient child-care support. ${ }^{36}$ The labor market is also relatively inflexible in terms of possibilities for part-time work or re-entering the labor force after an absence due to child-birth (González et al. 2000). This hinders the combination of female labor force participation and childbearing. In an European comparison, Italy and Spain also have among the lowest levels of state support for families with children in terms of tax allowances or direct transfers (Esping-Andersen 1999). While this deficit is partially compensated through strong family networks, as for instance through the provision of child-care or economic resources through grandparents (Reher 1997), this substitution of family support for public support is likely to be insufficient in contemporary industrialized countries. Moreover, the high integration of young adults in their parents' home and extended family may even discourage union formation and fertility (Dalla Zuanna 2001).

Family roles in the Southern European lowest-low fertility countries have also been slow in adapting to the new role of women (Chesnais 1996). Italy and Spain have among the most asymmetric labor divisions within households, and it is even more asymmetric after the birth of the first child (Palomba and Sabbadini 1993). The countries therefore 
conform with McDonald's (2000) argument about gender equity: fertility falls to very low levels when gender equity rises in individual-oriented institutions, like the labor market, while it remains low in family-oriented institutions.

The moderate and very low quantum in Eastern Europe is in part determined by similar institutional factors hindering high parity progression probabilities. In addition, many of the pronatalist - or at least family friendly - policies in CEE countries have discontinued after 1990 (Macura 2000), and the economic crisis has deteriorated particularly the high integration of women in the labor market. Furthermore, Eastern Europe is characterized by a persistence of economic insecurity throughout the life-course. This is in contrast to Southern Europe, where unemployment and economic stress are concentrated during early adulthood years. In Eastern Europe, the uncertain long-term outlook regarding unemployment, the housing situation and economic recovery implies that uncertainty affects not only the timing of the first birth but also transition to the second and higher-parity children.

While the above institutional context - at least in Southern Europe - has been relatively constant in recent decades, its effect on the quantum of fertility has not. In particular, the effect of this institutional context needs to be investigated paying an explicit attention to the rapid postponement in lowest-low fertility countries that has transformed the age-pattern of entering parenthood.

The delay of childbearing has been associated with substantially increased investments in higher education for females (see Table 7). Similarly, labor market experience prior to marriage and parenthood are likely to be higher for women with late childbearing than for women with early fertility. A direct consequence of these increased levels of female humancapital and labor market experience is an increase in the opportunity costs of childbearing in terms of foregone wages.

This relation between the timing of fertility and the wage-level is depicted by the broken line in Figure 4(a). The wage-level has been standardized so that it equals one for women with an early onset of parenthood. It increases with a later age at first birth because the delay in childbearing is generally associated with higher levels of human capital and labor-market experience that are rewarded in the labor market.

This rise in wages increases the opportunity costs of time spent outside the labormarket, and it increases the costs of time-intensive 'goods' such as children. The opportunity cost, however, is not so high as the wage level indicates since there can be some labor force participation. In particular, women with late childbearing can substitute away from 'own' child-care and into 'purchased' child-care (kindergarten, household help, etc.). This implies that the opportunity costs of children increase less steeply with delayed childbearing than the index of wages (for the moment we ignore other costs of children that may potentially depend inversely on the age at first birth, such as for instance health costs during pregnancy). ${ }^{37}$

The extent of this difference between wages and opportunity costs of children, however, depends on the compatibility of childbearing with female labor force participation. In a country with a low compatibility, the ability to arrange a flexible part-time work, or the ability to find a position that can be combined with institutional day-care, is limited. 
a) Wages, child-costs, and compatibility of fertility and female labor force participation

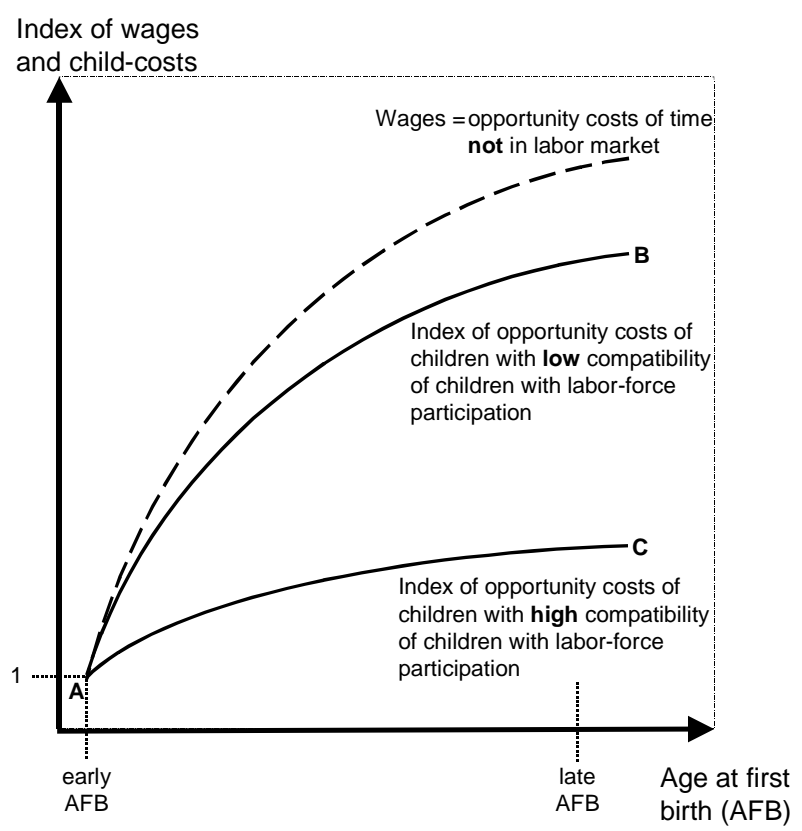

b) Postponement effect and compatibility of fertility and female labor force participation

Postponement

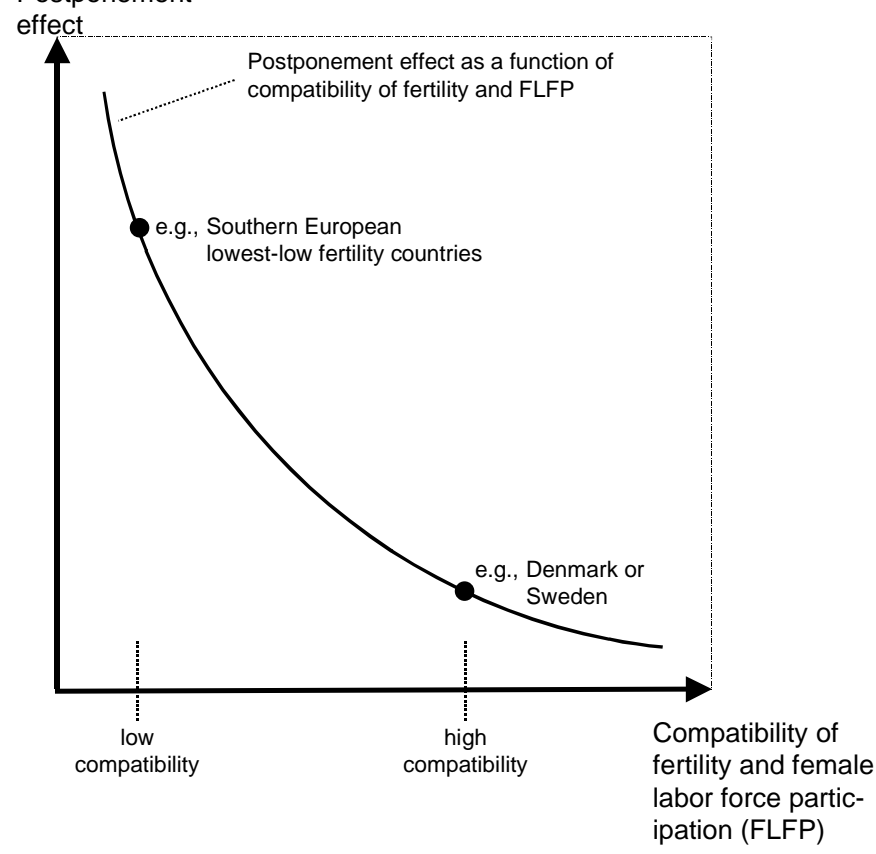

Postponement effect $=($ relative $)$ decline in completed

ertility associated with an additional

delay of childbearing by one year

Figure 4: Postponement of fertility, wages and childcosts 
Hence, the scope for the above substitution from time-at-home to time-in-the-labor-market is restricted. The postponement-induced increase in wages therefore translate into substantial increases in the opportunity costs of children (see line AB in Figure 4a). These higher child-costs will tend to reduce the quantum of fertility. ${ }^{38}$

If there is a high compatibility of childbearing and female labor force participation, wage increases associated with late childbearing lead to more modest increases in the opportunity costs of children (see line AC in Figure 4a). In particular, women will be able to shift relatively flexibly their time allocation from time-at-home to time-in-the-labormarket, and this substitution diminishes the effects of increased wages on child-costs. In addition, with high levels of female labor force participation there can also be a positive income effect on the demand for children.

These differences between countries with high and low compatibility of work and children have important implications for the causal effects of delayed childbearing on the quantum of fertility. In particular, the higher human-capital associated with delayed childbearing translates directly into increased opportunity costs of children. This effect is especially relevant when it is combined with the large delays in childbearing that occur during the postponement transition. In this case, the postponement-induced increases in child-costs during the postponement transition are likely to imply substantial declines in individual's demand for children of parity two or higher.

In our opinion, the above mechanism constitutes one of the key reasons why the postponement effects, which measure the reduction in completed fertility due to an additional year of delay in parenthood, are particularly strong in Southern Europe (see Section 3.1 and particularly Table 3). Socioeconomic conditions that provide incentives for individuals to delay childbearing, such as uncertainty in early adulthood, therefore indirectly increase the costs of children. Incentives to delay thus have an indirect negative impact on the desired number of children.

The postponement of fertility is therefore not neutral with respect to the quantum of fertility. Quite to the contrary, there is a negative association, and the magnitude of this postponement-quantum interaction depends on the compatibility of work and children (see Figure 4b). On the one hand, countries with low compatibility between female labor force participation and childbearing, such as Italy and Spain, are subject to large postponement effects. These countries therefore experience substantial reductions in completed fertility that are causally related to delayed childbearing. On the other hand, in countries with a high compatibility of work and children, as for instance Denmark or Sweden, the increased costs of time-at-home associated with delayed parenthood can be partially accommodated by increasing the labor force participation. These countries are therefore likely to have a smaller postponement effect, and late childbearing in itself does not imply strong reductions in the quantum of fertility.

\section{Summary: the determinants of lowest-low fertility}

In this section we briefly summarize the main determinants of lowest-low fertility that we have elaborated above. We have argued that lowest-low fertility, defined as a period TFR 
below 1.3 , is caused by a combination of demographic and socioeconomic factors:

a) Tempo- and distributional distortions of period fertility measures. The total fertility rate tends to underestimate the quantum of fertility $(i)$ during periods with a postponement of fertility due to tempo distortions, and (ii) in periods after a substantial decline and/or postponement of fertility due to compositional distortions. We discuss alternative adjusted measures, including the adjusted TFR and adjusted parity-progression probabilities. These measures suggest that current period fertility in Italy, Spain, Hungary or the Czech Republic is associated with a cohort fertility of approximately 1.3-1.5 in our postponement continues scenario, and with a cohort fertility of $1.5-1.7$ in the postponement stops scenario.

b) Socioeconomic incentives to delay childbearing. Almost all lowest-low fertility countries are characterized by a rapid postponement of fertility, and we argue that this postponement is a rational response to economic uncertainty in early adulthood, increased returns to education, shortages in the labor market, and similar factors that provide incentives to delay childbearing.

c) Social interaction effects on the timing of fertility reinforce the adjustment of individual's desired fertility to socioeconomic changes. In particular, social multiplier effects and multiple equilibria can give rise to postponement transitions that lead to rapid, persistent and generally irreversible delays in childbearing across a wide range of socioeconomic conditions.

d) Postponement-quantum interactions lead to reductions in completed fertility that are causally related to the delay in childbearing. Many lowest-low fertility countries share a generally weak state support for children that reduces the progression probabilities to higher parities. Most relevant in the Southern European context, however, is the incompatibility of female labor force participation and childbearing due to inflexible labor markets and insufficient day-care provision. These conditions imply that the increases in human-capital and labor market experience, which are associated with delays in childbearing, have important effects on child-costs. The postponement of fertility therefore does not only lead to a delayed pattern of childbearing. It also implies important negative effects on the quantum of fertility and on completed fertility.

The above four factors are not necessarily unique to lowest-low fertility countries. However, we believe that lowest-low fertility countries are characterized by a combination of all four factors in a particularly pronounced fashion. Lowest-low fertility is therefore the outcome of an interaction of demographic and behavioral factors that each in itself would lead to lower fertility. In combination and interaction, however, these factors enforce each other and lead to lowest-low fertility. 


\section{The future of lowest-low fertility: some speculations}

Four questions seem to be of central importance in assessing lowest-low fertility. First, is lowest-low fertility a permanent, long-term or merely a transient phenomenon that will disappear from the demographic landscape in the near future? Second, has lowest-low fertility already reached its lowest-low levels, or are future declines in fertility likely? Third, is the emergence of lowest-low fertility likely to be a wide-spread phenomenon, or will it remain restricted to regions such as Southern and Eastern Europe, where this pattern is currently concentrated? Fourth, has the postponement of childbearing in lowest-low fertility countries reached its limits and is this trend coming to a halt in the near future?

It is obvious that conclusive answers to these questions are far beyond the scope of this paper, and we believe the issues related to the above questions will importantly shape the demographic research in future years. Despite the daunting task of speculating about the future of lowest-low fertility, we will nevertheless embark on an attempt to map some future developments with respect to the above questions. ${ }^{39}$

In assessing the future of lowest-low fertility, it is noteworthy that substantial childlessness has not been a driving force leading to reduced fertility in the group of countries currently classified as lowest-low fertility countries. These relatively moderate levels of childlessness allow us to focus our speculations about the future of lowest-low fertility on two aspects: the future developments of the timing of fertility, and the future paths of the quantum of fertility for those women or couples who decide to have at least one child. ${ }^{40}$

We begin our speculations with indications about the 'physiological limits' to a postponement of fertility and the medical evidence about the feasibility of wide-spread childbearing above the ages of 30-35. Following Menken's (1985) PAA presidential address asking "How late can you wait?", a first detailed effort in weighing the medical pros and cons of late childbearing is the study by Beets et al. (1994). The study reviews several biomedical investigations in the early nineties. Most important in our context is that the study raises substantial skepticism about the possibilities of reliably realizing fertility intentions if the efforts to conceive start after age 35. Moreover, the study states that the current information available to women may not be sufficient to make them aware of the uncertainties associated with plans for childbearing after age 35. This potential lack of information about the feasibility of childbearing at advanced ages was even the theme of a Newsweek cover story 'The truth about fertility: Don't believe the hype even fertility specialists say younger is better' (Newsweek, August 27, 2001). The cover story also refers to a new generation of celebrities who seem to be new 'trend-setters' by having their first babies in their $20 \mathrm{~s} .{ }^{41}$

Findings of a study on natural fertility populations show that for the most part,declining fecundity with maternal age is a result of aging at the level of the ovaries (O'Connor et al. 1998). In particular, in the peri-menopausal years, which are of key interest when looking at the possibilities of postponing childbearing, declining fecundity is a function of both declining fecundability and increasing risk of fetal loss (Wilcox et al. 1988), much of which is due to chromosomal abnormalities. In a longitudinal study on population register data from Denmark, Andersen et al. (2000) found that maternal age at conception is a strong 
and independent risk factor for fetal death, independently of reproductive history and they conclude that the general chances of successful pregnancies in women aged 40 and over are poor. ${ }^{42}$

Our reading of the medical literature suggests a general skepticism and controversy about the feasibility of widespread and sufficiently reliable childbearing above age 35, especially for first children. Moreover, as far as we can assess, there is no convincing evidence that opportunities for successful and reliable childbearing at older ages are improving at a rate that is compatible in the medium and long term with the currently observed trends toward delayed childbearing. In vitro fertilization, intra uterine insemination and oocyte donation, may partially overcome some of these age-related problems. However, comprehensive evidence about the extent to which these developments can facilitate wide-spread very late fertility on the population level does not yet exist.

In lieu of conclusive evidence in the medical literature about the limits of postponed childbearing, we may also turn to aggregate country-level evidence about the potential endpoints of the postponement. The observations of country experiences prior to the late 1990s does not necessarily provide an indication about 'limits' to the postponement of fertility. It is clear that many $\mathrm{CEE}$ countries with still relatively early childbearing can continue the postponement of birth, even at relatively rapid annual rates such as an annual increase in the mean age at first birth by .2, for at least two to three decades until they reach the late age-patterns of fertility currently observed among Northern and Southern European countries. During this period there may also be little reason to expect that the period fertility will rise because tempo distortions caused by the postponement of fertility diminish.

The short- and medium-term limits to postponement are equally ambiguous for other lowest-low fertility countries characterized by late childbearing, and the same pertains more generally to the leading countries in fertility postponement. These countries have experienced substantial increases in the mean age at birth, and in some cases there has been a recent slow-down in the annual increases in the mean age at first birth. Yet, there is not a single lowest-low fertility country in which the mean age at first birth has stabilized for several consecutive years at a level that could be perceived as the latefertility equilibrium or the endpoint of fertility postponement. It is clear that the upper age-limit to childbearing prevents substantial future postponement without changing the age-pattern of parity-specific fertility rates or childbearing intensities. However, a differential postponement of fertility across age-groups can continue for a considerable time, even in those countries that already exhibit very late childbearing patterns. For instance, borrowing a popular idea on human longevity, one may foresee a rectangularization of fertility patterns. This rectangularization, which needs not be only a feature of lowest-low countries but of all below-replacement fertility countries, is characterized by a concentration of childbearing in an increasingly narrow age-interval. In this scenario, few women will have children prior to, say, age 28 or 29, and childbearing at parity one and two will be concentrated when women are in their thirties. There will be very few higher parity births, especially among women with a late onset of childbearing. A first indication of such a potential rectangularization of fertility in Spain, the Netherlands and Sweden is 
found by Kohler and Ortega (2001c), where the most recent increases in the mean age of the intensity schedule for parity one have been associated with a decreasing standard deviation. In Spain, for instance, the standard deviation declined from 5.4 to 4.7 (-11\%) during 1980-98, while the mean increased from 26.7 to 30.8 ( $+16 \%)$. This trend towards a rectangularization is also revealed by the interquartile range in the age at first birth (for a related application to mortality, see Wilmoth and Horiuchi 1999). This interquartile range is the difference between the ages when $25 \%$ and $75 \%$ of women, who ultimately experience a first birth, have entered parenthood. In a synthetic cohort experiencing the 1980 (tempo-adjusted) childbearing intensities in Spain, for instance, this interquartile range is equal to 7.0 years, and it is reduced to 5.2 years in a cohort that experiences the 1998 childbearing intensities. ${ }^{43}$ These declines in the standard deviation and the interquartile range suggest a beginning concentration of fertility into a more narrow age interval, and it indicates that pure increases in the mean age may start to reach their limits.

In summary, the analyses of country-level data about the mean age at birth and parityspecific birth rates or childbearing intensities do not necessarily suggest that the postponement will come to a halt in the near future. Moreover, we consider further increases in the mean age at first birth, combined with a rectangularization of the fertility age-pattern, a quite likely outcome in countries that already have patterns of childbearing.

The future development of the quantum of fertility is of course an additional major determinant of long-term period and cohort fertility levels. Extensive and comprehensive discussions of this aspect are for instance included in Bongaarts and Bulatao (2000), Lesthaeghe and Willems (1999) or Golini (1998). ${ }^{44}$ Here we focus on the question of whether lowest-low fertility is likely to decline further due to an ongoing delay of childbearing.

In the Southern-European lowest-low fertility countries, which were the first to fall persistently below a TFR of 1.3, our analyses suggest that the periods with the most rapid pace of postponement may have already passed. Tempo-distortions in the total fertility rate are therefore unlikely to rise, and the annual increases of the mean age at first birth may start to decline in the next years. In combination with a constant quantum of fertility, this suggests that lowest-low fertility in Italy and Spain may have reached its trough and will either stabilize or slowly reverse. However, our discussion of postponement-quantum interactions in Section 4.5 suggests that further delays in childbearing are likely to reduce the quantum of fertility, and this can (partially) compensate for the positive effect resulting from reduced tempo distortions. Despite this potential reversal of period fertility, many cohorts in Southern Europe will remain at below replacement fertility almost irrespective of the future fertility developments in the next decades. This is due to the already late childbearing in these countries that leaves little scope for a future recuperation of fertility.

The situation is somewhat different in Central and Eastern European countries that still exhibit a relatively young mean age at birth. Due to the potential for considerable future delays in childbearing, we do not foresee that tempo-distortions lose their relevance in CEE countries. Unless there are changes in the quantum, for instance due to improved economic conditions and reductions in uncertainty, we expect that lowest-low fertility will prevail for a considerable time, say 20-30 years. Moreover, a potential further decline in 
period fertility due to tempo-distortions seems likely in countries like Bulgaria, Russia or Ukraine, which have attained lowest-low fertility without exhibiting a strong postponement of childbearing. If the transition to late-childbearing in these countries gains the pace observed in the Czech Republic or Hungary, then additional tempo distortions can suppress the period total fertility rate substantially below the current levels of 1.1-1.3.

A final issue in the context of lowest-low fertility pertains to the mechanisms that could potentially lead to a reversal of this pattern. In addition to a diminishing role of tempo-distortions, fertility levels could stabilize or recover due to a wide range of factors that affect the quantum and desired level of fertility. On one hand, increases in the quantum of fertility can occur due to improvements in the economic situation, especially for young adults or in transition countries. Some empirical evidence suggests that better economic conditions for young adults lead to earlier transitions to adulthood, marriage, and fertility (Aassve et al. 2001; Ahn and Mira 2001). On the other hand, more generous social policies could create a socioeconomic environment that provides increased incentives for having children, including for instance child-care provision, better access to labor markets for women with children, and transfers to families with children. Due to the relatively low levels of childlessness, these policies in lowest-low fertility countries should be targeted in particular towards the realization of delayed first births at higher ages and the progression from the first to the second child. Potentially effective interventions have been extensively discussed elsewhere (Demeny 1999; McDonald 2000; Teitelbaum 1999). In light of our discussion of postponement-quantum interactions in Section 4.5, interventions that increase the compatibility of work and children are particularly important, especially in lowest-low fertility countries with very late patterns of childbearing. However, none of the current lowest-low countries has implemented significant policy changes with the goal of increasing fertility, despite the considerable public debate about declining birth rates (e.g., see Stark and Kohler 2000). This lack of policy response may also be due to the fact that several scholars have raised skepticism about the extent to which policy measures can substantially influence demographic behavior (see the review paper by Gauthier 2001).

We conclude our speculations with a potential demographic mechanism that implies homeostatic forces and could potentially lead to increased quantum of fertility in the future. In particular, persistent lowest-low fertility leads not only to a rapid aging of the population with its well-known problems for social security and related transfer programs, but it also leads to substantially reduced relative cohort sizes. For instance, the first lowestlow fertility cohorts born early in the 1990s in Italy and Spain are about $41 \%$ smaller than the cohorts born 25 years earlier. ${ }^{45}$ In the next 10-20 years, when these small cohorts begin higher education, or begin to enter the labor and housing markets, they are likely to face substantially more favorable conditions than their 25-year older predecessors, who have contributed importantly to the emergence of lowest-low fertility in the 1990s. This positive effect of cohort size, first proposed by Easterlin in the context of the U.S. baby boom (for a summary of these arguments, see Easterlin 1980), seems particularly likely given the limited international migration into lowest-low fertility countries. These positive experiences in the labor and housing market during early adulthood may contribute to an increase in both period and cohort total fertility rates. ${ }^{46}$ Despite its speculative character, 
this effect may nevertheless be important since it is likely to be one of the few demographic factors with homeostatic implications that can lead to a reversal of lowest-low fertility.

The outlook on the future of lowest-low fertility in this section clearly indicates that this pattern is unlikely to be a short-term phenomenon that will quickly disappear from the demographic landscape. In our opinion, lowest-low fertility is likely to be a persistent pattern. We expect that it prevails for a considerable period in the CEE countries with a TFR below 1.3. In addition, we believe that lowest-low fertility is likely to spread in the near future to several other countries that currently experience a TFR between 1.3 and 1.5. These 'lowest-low fertility candidates' include Austria, Germany, several Central and Eastern European countries like Poland, Lithuania, Slovakia, Croatia, and Asian countries like Korea and Japan. Moreover, other South-East Asian countries might possibly cross the lowest-low barrier. In particular, a recent study on low fertility in urban China (Zhao 2001) has shown that the one-child policy reduced the total fertility rate of urban China to a level of 1.15 in 1980 .

Acknowledgments: The authors wish to thank the Advisory Group of the FFS programme on comparative research for its permission, granted under identification number 75 , to use FFS data. The views expressed in this paper are attributable to the authors and do not necessarily reflect those of the Max Planck Institute for Demographic Research. 


\section{Notes}

${ }^{1}$ The calculations are obtained using the approximation that the growth rate $r$ in the stable population is approximately given by $r=\log (N R R) / \mu$, where $\mu$ is the overall mean age at birth and the $N R R$ is calculated as $N R R=.4886 * T F R$. We use $\mu=30$, which is a roughly representative mean age for contemporary Western European countries, and $T F R=1.3$ for the calculations in the text. In terms of the stable-population implications, a total fertility rate of 1.3 is the mirror image of a TFR of approximately 3.2 , which implies an annual growth rate of $+1.5 \%$ and a doubling of the birth cohort and population size every 45 years.

${ }^{2}$ Nevertheless, intentionally low fertility seems to have played a role in some of the population declines recorded in history like the native South and Central Americans after the conquest (Sánchez-Albornoz 1974).

${ }^{3}$ Based on Coale's (1986) $I_{f}$ index multiplied by 12.44, marital fertility level of the Hutterites.

${ }^{4}$ The list of lowest-low fertility districts, based on Coale (1986), includes Vienna, Sussex, Hampshire, Northamptonshire, Berlin, Oslo, Stockholm, Basel, Geneva. Based on Kirk (1946) we would add to the list Hamburg, Saxony, Bremen and Riga.

${ }^{5}$ There have been large regional differences within Germany since 1990. East Germany, i.e. the region of the former GDR, has experienced lowest-low fertility since 1991 with rates below 1 between 1991 and 1996, while West Germany has experienced a TFR close to 1.4 throughout the 1990s. For a discussion of the specific East German situation, see for instance Eberstadt (1994) or Witte and Wagner (1995).

${ }^{6}$ See for instance Feeney and Yu (1987) for a discussion of this issue in the context of the fertility decline in China and the one-child family policy.

${ }^{7}$ Childbearing intensities, or rates of the first kind, relate births of a given order to women who are exposed to this parity; for instance, first births are related to the number of childless women in each age group.

${ }^{8}$ For a related discussion of the relation between period and cohort fertility, see van Imhoff (2001).

${ }^{9}$ For a detailed analyses of the U.S. case, see Morgan and Rindfuss (1999).

${ }^{10}$ For a detailed discussion of this estimation and its interpretation, see Kohler et al. (2001).

${ }^{11}$ Bongaarts and Feeney derive a simple formula to calculate this adjusted total fertility rate by dividing the observed parity-specific TFR by $1-r_{i}$, where $r_{i}$ is the change in the mean age at childbearing for birth-order $i$.

${ }^{12} S$-plus programs to perform these calculations are available at http://user.demogr.mpg.de/kohler.

${ }^{13}$ The data were provided by the Observatoire Démographique Européen and include age- and parity specific childbearing intensities (rates of the first kind) and fertility rates (rates of the second kind) for cohorts born from approximately the 1930s onward.

${ }^{14}$ For Spain, comparable data for childbearing intensities have been computed from census, registration and survey data by the authors. Vital registration in Spain provides information on births by parity, cohort and age since 1975. The parity distribution of women has not been previously reconstructed and is subject to a big lack of information since the census provides tabulations only for five-year age groups. For those cohorts where the complete fertility path is available, we have used the fertility rates to reconstruct cohort parity distributions. For the remaining cohorts we have used a mixture of an imputed parity distribution based on fertility at the beginning of the period, and the observed parity distribution in 1991 which has 
been kindly provided to us by Namkee Ahn as tabulated from the large 1991 Sociodemographic survey (sample over 100,000). We are quite confident that the reconstruction of the parity distribution of the population is accurate in relatively recent years, while some uncertainty exists in the construction of the parity distribution, especially at higher parities, in early years.

${ }^{15}$ The averaging merely reduces the role of period-specific influences and the results do not change if the calculations are performed for single years without averaging.

${ }^{16}$ For an application of the Bongaarts-Feeney fertility adjustment to Central and Eastern European countries, see Philipov and Kohler (2001), and for an application to Spain, see Ortega-Osona and Kohler (forthcoming).

${ }^{17}$ There is some interesting heterogeneity in contraceptive use across lowest-low fertility countries. Abortion is especially practiced in the CEE countries, with generally more abortions registered than births (Bankole et al. 1999). In Southern Europe, the use of traditional methods is still very frequent (Spinelli et al. 2000).

${ }^{18}$ For a discussion of evolving fertility desires, see for instance Arroyo and Zhang 1997 or Lee 1980.

${ }^{19}$ In addition, see Aassve et al. (2001) for an investigation of home-leaving in Italy, and Giannelli and Monfardini (2000a) and Martikainen and Valkonen (1998) for an analysis of the relationship between unemployment, additional education and later home-leaving. See Cantó-Sánchez and Mercader-Prats (2000) for a study of poverty reduction connected with these strategies.

${ }^{20}$ See also Saget (2001) for a critical assessment of unemployment trends in the transition countries.

${ }^{21}$ For a general perspective see Munich et al. (1999) or Newell and Reilly (2000). On the correlates of poverty in the transition countries see the general view in Milanovic (1998) and Grootaert and Braithwaite (1998). More specific views of demographic interest are Forster and Toth (2000), Lokshin and Yemtsov (2001) and Philipov (2001). Relevant country-specific studies include Kohler and Kohler (1999); Noorkoiv et al. (1997); Orazem and Vodopivec (1995, 1999); Paternostro and Sahn (1999); Rutkowski (1996); Vercernik (1995).

${ }^{22}$ A notable exception is Bulgaria, where female university enrollment has substantially increased despite a precarious economic situation. Contrary to the pattern in other countries with similar increases in the enrollment, however, the postponement of fertility postponement has been very slow. This increase in education despite the severe economic crisis may be due to changes in the enrollment procedure for universities. Before 1989, the access to university education was quite limited. Prospective students were required to take exams, and only the most qualified were admitted into universities. Moreover, it was possible to apply for enrollment in only one field of study and only one university. After 1989, the system has changed and access to higher education has been simplified, including less restrictive selection and the possibility to enroll in more than one university and for more than one field of study (personal communication with Iliana Kohler).

${ }^{23}$ For instance, in the former countries of the Soviet Union countries, where the economic situation was and continues to be most unstable, the proportion pursuing higher education has decreased. In Armenia the ratio has almost halved from an already low level in 1989. In Russia, women seem to have reduced their enrollments in higher education, whereas in Belarus this reduction of human capital investments seems to pertain to males. There has also been a decline in Ukraine, and the exception among these countries is Georgia with moderate increases in both male and female enrollment ratios.

${ }^{24}$ Even in the absence of uncertainty, models of optimal age at childbearing would predict delayed parenthood in response to increased returns to education (Gustafsson 2001b; Happel et al. 1984). The specific situation in countries with considerable labor-market or income uncertainty is likely to make this response even stronger due to strategic postponement. For instance, Ranjan (1999) shows a simple two- 
period model where it is optimal to postpone childbearing in times of increased income uncertainty. This strategy reduces the probability that a child is born in the first period and parents are subject to falling income levels in the second period. This strategic postponement leads to some distinct and observable consequences. In particular, in order that individuals have children at all, the foreseeable scenarios must include situations where they desire children. This desire, however, is linked to welfare in the future. On the one hand, a good economic performance in the future would increase fertility and it would be associated with a higher age at childbearing. If there is a bad economic performance, on the other hand, fertility might continue to be low with the mean age at childbearing determined by the non-postponers. This explanation may underlie the relative stability of the mean age at childbearing in the countries facing more hardship during the transition, such as Belarus, Russia or Ukraine.

${ }^{25}$ Guiso and Jappelli (1999) document that economic transfers from the parents contribute to both earlier home-leaving from their siblings and more expensive housing. There are also sizeable effects of local housing prices on the timing of home-leaving Giannelli and Monfardini (2000a,b); Martikainen and Valkonen (1998), and in combination with the substantially increased housing prices in recent decades this may constitute an important determinant of the large delays in leaving the parental home.

${ }^{26}$ An indication of this complexity is the fact that many economic models of inter-temporal fertility choice are only solvable with highly simplistic assumptions, such as the absence of uncertainty about future socioeconomic conditions or very simple functional assumptions about the utility function (Gustafsson 2001a; Hotz and Miller 1988; Wolpin 1984). With more realistic assumptions, the optimal birth timing can often be obtained only numerically via quite computer-intensive dynamic algorithms.

${ }^{27} \mathrm{~A}$ recent qualitative study of women in the area of Lombardy in northern Italy has started to collect evidence about these interactions, and this study provides a first indication for the importance of social learning processes in a lowest-low fertility context. For instance, a 34 year old mother of one child reports "There are those who decide to stay at home for the family. [...] [My] neighbor for instance, she tells me she repented having decided to stay at home. She stayed at home with her children, she grew them up and all the rest, but now she says, 'well I am at home the whole day' and she suffers because of that [...] Re-entering the labor market, she says 'how can I do that now?' [...] she does not have any need to do it economically, not at all, it is just the idea of going out, out of the house, be in contact with other people, outside." (Bernardi 2001)

${ }^{28}$ For instance, there is evidence about age-norms for first marriage or first birth that 'prescribe' a socially appropriate behavior with respect to the timing of fertility or marriage. In a sociodemographic survey in Friuli-Venezia Giulia, one of the areas with the lowest fertility levels in Italy, among women aged 23-25, $58 \%$ of them said that there is a lower acceptable age limit for entering a union, and $81 \%$ said so for the birth of a child (Billari and Micheli 1999). Using event history modeling, Billari (2001) found that latent age limits may explain actual behavior as observed from cohort micro-data. There is also evidence from quantitative studies that sequencing norms discourage individuals (in particular women) not to become parents while they are students (Blossfeld and Huinink 1991). These two aspects are also reflected in Bernardi's (2001) qualitative interviews in the Lombardy area in Italy, where one woman (36 years old, one child) reported: "Actually I wanted to follow [university studies in] medicine, but my parents did not allow me because they said that it was too long a career for a woman [...] Yes, the condition my parents gave me was this one: 'first you get your degree and then you marry'. And I kept the promise." A further relevant norm pertains to the sequencing of marriage and childbearing, or out-of-wedlock childbearing, and these norms seem to be particularly relevant in some lowest low fertility countries such as Italy and Spain that exhibit among the lowest rate of out-of-wedlock births (Kiernan 1999). Such sequencing norms will tend to raise the socially desirable age at childbirth since childbearing has to be postponed, at least for a vast majority, until after marriage, and this effect is reinforced if marriage and education are perceived as incompatible.

${ }^{29}$ Formal models of normative change caused by social interactions are for instance presented in Bicchieri and Skyrms (1997), Bernheim (1994), Brock and Durlauf (2001), Young (1993) or Kohler (2000a, 2001). 
${ }^{30} \mathrm{~A}$ formal analysis of these marriage market interactions is for instance provided in Goldin and Katz (2000), and this study also provides a detailed investigation of how women's human capital investments in the United States were affected by the introduction of the pill that provided an effective and reliable method of controlling and delaying fertility.

${ }^{31}$ Similar feedback mechanisms operating through the labor supply are also a driving factor in Easterlin's (1980) theory of fertility fluctuations.

${ }^{32}$ For a discussion of the characteristics of the fertility transition in Europe or contemporary developing countries, see for instance Coale and Watkins (1986) or Bongaarts and Watkins (1996).

${ }^{33}$ In principle it is conceivable that there is a reversal in the age-pattern of fertility. In a multipleequilibria situation, however, such reversals of significant increases in the mean age at parenthood are unlikely in the absence of policy interventions or substantial socioeconomic changes that favor earlier childbearing. Moreover, due to the stability of the late-fertility equilibrium, only large policy interventions could induce such a shift, whereas small interventions are likely to have only marginal effects (for related discussions, see Kohler 2000b; Kohler et al. 2000). The various policy measures implemented in the GDR to induce relatively early childbearing may be one example of such a successful policy intervention (for a discussion of these policies, see for instance Cornelius 1990).

${ }^{34}$ Ideational factors have been particularly emphasized in the Second Demographic Transition theory that describes the emergence of below replacement fertility, delayed childbearing and the rise of cohabitation in Western Europe; see for instance Lesthaeghe (1983) or van de Kaa (1987).

${ }^{35}$ For a related discussion of convergence, see (Wilson 2001).

${ }^{36}$ In the 1980s, for instance, the share of children below age 3 with day-care coverage in Southern Europe was $4.7 \%$, with respect to $9.2 \%$ in Continental Europe (Austria, Belgium, France, Germany and the Netherlands) and $31.0 \%$ in the Nordic countries (Denmark, Finland, Norway and Sweden) (EspingAndersen 1999).

${ }^{37}$ For a discussion of economic models of fertility, and specifically also the value-of-time model on which this example is based, see Willis (1973), Becker (1981) or Cigno (1991). A detailed economic model of the postponement effect and its relation to the age at first birth is discussed in Kohler et al. (2001). Recent analyses of mother's or parents' time spent with children in the U.S. include Bianchi (2000) and Sandberg and Hofferth (2001).

${ }^{38}$ In addition to the 'price effect' caused by increases in female wages there is also an 'income effect' in the opposite direction; empirically - although not necessarily theoretically - the negative price effect strongly dominates the positive income effect.

${ }^{39}$ The reader may also refer to related discussions in Lesthaeghe and Willems (1999), Bongaarts and Bulatao (2000) and Coleman (1996).

${ }^{40}$ This pattern may change when some of the current lowest-low candidates, such as Germany or Austria, reach a total fertility of 1.3 or below. In West Germany, for instance, about $26 \%$ of women in the 1959 cohort are childless (Eurostat 2001) and childlessness is expected to be above $1 / 3$ in younger cohorts (Dorbritz and Gärtner 1999). Some additional aspects, not emphasized in the present paper, are likely to become important once countries with such high childlessness reach lowest-low fertility. In particular, a central question in these countries is the polarization of fertility behavior and the determinants that lead to this divergence in fertility-related behaviors between those who have at least one child (frequently associated with marriage or long-term cohabitation) and those who will remain childless (and frequently also single).

${ }^{41}$ The examples mentioned in the article include Belgium's Princess Mathilde, Jade Jagger, French model 


\section{Laetitia Casta and acress Kate Winslet.}

${ }^{42}$ Long-term trends in the age limits to conceive are also of crucial importance for assessing the limits of a potential postponement. Bongaarts (1983) reports that in natural fertility populations in different historical settings, the median age of women at last birth is around 40/41 years. When age limits are concerned, age at menopause is considered to be an almost perfect marker of the reproductive life-span for women (te Velde et al. 1998; van Zonneveld et al. 2001). The average age at menopause is about 50-51 years in Western countries, and it shows a remarkable variation between women from 40 to 60 years. Nulliparous women have been shown to have an earlier menopause with respect to women that have had pregnancies, and in general age at menopause increases with the parity (Kaufert et al. 1987). On the other hand, the use of oral contraceptives may increase age at menopause (Van Noord et al. 1997). Thus, the overall impact on age at menopause and on the age limits to conceive of postponing births (including the first birth) on age while using oral contraceptives is not a priori clear.

${ }^{43}$ The calculations first compute the probability $P(x)$ of having a first birth prior to age $x$ for women in a synthetic cohort who experiences the adjusted period childbearing intensities in a calendar year. We then condition on giving birth to at least one child and compute $\tilde{P}(x)=P(x) / P(15)$, where 15 is the youngest age at childbearing. We then use linear interpolation to calculate the ages where $\tilde{P}(x)$ equals .25 and .75. The interquartile range is the difference between these ages.

${ }^{44}$ There have also been several theoretical approaches that try to find the 'limits' of low fertility. In a recent review of the arguments based on biological dispositions, social coercion and rational-choice arguments, for instance, Morgan and King (2000) discuss the question of why individuals in the $21^{\text {st }}$ century have children at all, despite the large economic costs associated with children. The authors are skeptical, but not ultimately pessimistic, that developed countries can succeed in establishing a socioeconomic context that would facilitate relatively high levels of fertility in the long term. Foster (2000) argues that low fertility may have reached its limit since an innate 'need to nurture', in conjunction with normative pressures, ensures that the majority of women will want to bear at least one child (Several related studies have also been able to document genetic influences on fertility and fertility related behaviors; for instance, see Kohler et al. 1999; Rodgers et al. 2001). Golini (1998), on the other hand, argues that period TFRs of about 0.8 , such as those observed in the former GDR and in the Italian Province of Ferrara in 1994, are close to the possible minimum levels of period fertility. He also hypothesizes that values of between 0.7 and 0.8 children per woman are conceivable minima for cohort fertility. These minimum levels are derived by arguing that a fraction of $20-30 \%$ of women at most remains childless, and the remaining woman have primarily one child to satisfy parenthood desires, and only few two children.

${ }^{45}$ We compare the cohort born in the first year in which the TFR fell below 1.3, i.e., the year of onset of lowest-low fertility, and the cohort born 25 years earlier. The respective cohort sizes are 549,484 (1993) and 930,172 (1968) in Italy, and 396,747 (1992) and 680,125 (1967) in Spain (Council of Europe 2000).

${ }^{46}$ In particular, Macunovich (1998) discusses the possibility that these effects operate mainly through tempo change and only secondarily through quantum. If smaller cohorts benefit from an easier entry into the labor and housing market, this may particularly lead to faster transitions into marriage and parenthood. Quantum changes primarily occur because the tempo-quantum discussed in Section 4.5 are reversed. 


\section{References}

Aassve, A., F. Billari, and F. Ongaro (2001). The impact of income and employment status on leaving home: Evidence from the Italian ECHP sample. Labour 15, 501-530.

Ahn, N. and P. Mira (2001). Job bust, baby bust: Evidence from Spanish data. Journal of Population Economics 14(3), 505-522.

Andersen, A.-M. N., J. Wohlfahrt, P. Christens, J. Olsen, and M. Melbye (2000). Maternal age and fetal loss: A population based linkage study. British Medical Journal 320, 17081712 .

Arroyo, C. R. and J. Zhang (1997). Dynamic microeconomic models of fertility choice. Journal of Population Economics 10(1), 23-65.

Bankole, A., S. Singh, and T. Haas (1999). Characteristics of women who obtain induced abortion: A worldwide review. International Family Planning Perspectives 25(2), 6877.

Becker, G. S. (1981). A Treatise on the Family. Cambridge, MA: Harvard University Press.

Beets, G., E. te Velde, P. Verloove-Vanhorick, H. Merkus, and H. Bruinse (1994). Medical complications of aging fertility. In G. Beets, H. van den Brekel, R. Cliquet, G. Dooghe, and J. de Jong Gierveld (Eds.), Population and Family in the Low Countries 1993: Late Fertility and Other Current Issues, pp. XXXX. Swets.

Bernardi, L. (2001). Personal network and reproductive choices: Evidence from a low fertility context. Dissertation research in progress, Max Planck Institute for Demographic Research, Rostock Germany.

Bernheim, B. D. (1994). A theory of conformity. Journal of Political Economy 102(5), 841-877.

Bianchi, S. M. (2000). Maternal employment and time with children: Drastic change of suprising continuity. Demography 37(4), 401-414.

Bicchieri, Christina Ed.and Jeffrey, R. E. and B. E. Skyrms (1997). The Dynamics of Norms. Cambridge: Cambridge University Press.

Billari, F. C., M. Castiglioni, T. Castro Martín, F. Michielin, and F. Ongaro (forthcoming). Household and union formation in a Mediterranean fashion: Italy and Spain. In E. Klijzing and M. Corijn (Eds.), TBA, pp. forthcoming. United Nations, Geneva.

Billari, F. C. and A. C. Liefbroer (2001). Should I stay or should I go? The impact of age norms on leaving home. Paper presented at the Annual Meeting of the Population Association of America, Washington, D. C. 
Billari, F. C. and G. A. Micheli (1999). Le scelte demografiche. La percezione dei costi e delle norme sociali. In L. Mauri and F. C. Billari (Eds.), Generazioni di donne a confronto. Indagine sociodemografica., pp. 163-190. Milano: Franco Angeli.

Billari, F. F. (2001). A log-logistic regression model for a transition rate with a starting threshold. Population Studies 55(1), 15-24.

Blossfeld, H.-P. and J. Huinink (1991). Human capital investments or norms of role transition? How women's schooling and career affect the process of family formation. American Journal of Sociology 97(1), 143-168.

Bongaarts, J. (1983). The proximate determinants of natural marital fertility. In R. A. Bulatao and R. D. Lee (Eds.), Determinants of Fertility in Developing Countries, pp. 103-138. New York: Academic Press.

Bongaarts, J. and R. A. Bulatao (Eds.) (2000). Beyond Six Billion: Forecasting the World's Population, Washington, DC. National Academy Press.

Bongaarts, J. and G. Feeney (1998). On the quantum and tempo of fertility. Population and Development Review 24(2), 271-291.

Bongaarts, J. and S. C. Watkins (1996). Social interactions and contemporary fertility transitions. Population and Development Review 22(4), 639-682.

Bourgeois-Pichat, J. (1976). Baisse de la fecondite et descendance finale. Population 31(6), 1045-1097.

Bourgeois-Pichat, J. (1979). La baisse actuelle de la fecondite en Europe s'inscritelle dans le modele de la transition demographique? Population 34(2), 267-305.

Brock, W. A. and S. N. Durlauf (2001). Discrete choice with social interactions. Review of Economic Studies 68(2), 235-260.

Bumpass, L. L. and E. K. Mburugu (1977). Age at marriage and completed family size. Social Biology 24(1), 31-37.

Bumpass, L. L., R. R. Rindfuss, and R. B. Janosik (1978). Age and marital status at first birth and the pace of subsequent fertility. Demography 15(1), 75-86.

Cantó-Sánchez, O. and M. Mercader-Prats (2000). Poverty among children and youth in Spain: The role of parents and youth employment status. Estudios sobre la Economía Española, EEE-14, FEDEA [www.fedea.es].

Chesnais, J.-C. (1996). Fertility, family, and social policy in contemporary Western Europe. Population and Development Review 22(4), 729-739.

Cigno, A. (1991). Economics of the Family. Oxford: Clarendon Press. 
Coale, A. J. (1986). The decline of fertility in Europe since the eighteenth century as a chapter in demographic history. In A. J. Coale and S. C. Watkins (Eds.), The Decline of Fertility in Europe, pp. 1-30. Princeton: Princeton University Press.

Coale, A. J. and S. C. Watkins (Eds.) (1986). The Decline of Fertility in Europe, Princeton. Princeton University Press.

Coleman, D. (1996). Europe's Population in the 1990s. Oxford: Oxford University Press.

Cornelius, I. (1990). Familien und Bevölkerungspolitik in der DDR. Arbeit und Sozialpolitik 8/9, 308-316.

Council of Europe (2000). Recent Demographic Developments in Europe. Strasbourg: Council of Europe Publishing.

Dalla Zuanna, G. (2001). The banquet of aeolus: A familistic interpretation of Italy's lowest low fertility. Demographic Research [Online available at http://demographicresearch.org] 4(5).

Dasgupta, P. (2000). Population and resources: An exploration of reproductive and environmental externalities. Population and Development Review 26(4), 643-690.

De Sandre, P. (2000). Patterns of fertility in Italy and factors of its decline. Genus 56(1-2), $19-54$.

Delgado, M. and T. Castro Martín (1998). Fertility and Family Surveys in Countries of the ECE Region, Standard Country Report Spain. Geneva: United Nations.

Demeny, P. (1999). Policy interventions in response to below-replacement fertility. Population Bulletin of the United Nations 40/41, 183-211.

Dolado, J. J., F. Felgueroso, and J. F. Jimeno (2000a). Explaining youth labor market problems in Spain: Crowding-out, institutions, or technology shifts. IZA Discussion Paper No.: 142, Bonn.

Dolado, J. J., F. Felgueroso, and J. F. Jimeno (2000b). Youth labour markets in Spain: Education, training and crowding-out. European Economic Review 44, 943-956.

Dorbritz, J. and K. Gärtner (1999). Berechnungen zur Kinderlosigkeit am Bundesinstitut für Bevölkerungsforschung. BIB-Mitteilungen 20(22), 13-15.

Duce Tello, R. M. (1995). Un modelo de elección de tenencia de vivienda para España. Moneda y Crédito (201), 127-152.

Easterlin, R. A. (1980). Birth and Fortune: The Impact of Numbers on Personal Welfare. Chicago: University of Chicago Press.

Eberstadt, N. (1994). Demographic shocks after communism: Eastern Germany 1989-93. Population and Development Review 20(1), 137-152. 
Entwisle, B., R. D. Rindfuss, D. K. Guilkey, A. Chamratrithirong, S. R. Curran, and Y. Sawangdee (1996). Community and contraceptive choice in rural Thailand: A case study of Nang Rong. Demography 33(1), 1-11.

Esping-Andersen, G. (1999). Social Foundations of Postindustrial Economies. Oxford: Oxford University Press.

Eurostat (2001). New Cronos Database: Population and Social Conditions. Brussels: Eurostat.

Feeney, G. and J. Yu (1987). Period parity progression measures of fertility in China. Population Studies 41, 77-102.

Festy, P. (1979). La fécondité des pays occidentaux de 1870 a 1970. Travaux et Documents, Cahier no. 85, INED - Presses Universitaires de France.

Festy, P. (1984). Effets et répercussion de la premiére guerre mondiale sur la fécondité française. Population 39(6), 977-1010.

Forster, M. F. and I. G. Toth (1997). Poverty, inequalities and social policies in the Visegrad countries. Economics of Transition 5(2), 505-510.

Forster, M. F. and I. G. Toth (2000). Trends in child poverty and social transfers in the Czech Republic, Hungary and Poland: Experiences from the years after transition. Luxemburg Income Study Working Paper No. 226.

Foster, C. (2000). The limits to low fertility: A biosocial approach. Population and Development Review 26(2), 209-234.

Fraboni, R. and F. F. Billari (2001). Measure and dynamics of marriage squeezes: from baby boom to baby bust in Italy. Max Planck Institute for Demographic Research, Rostock, Germany, Working Paper \#2001-005 (available at http://www.demogr.mpg.de).

Frejka, T. (1980). Fertility trends and policies: Czechoslovakia in the 1970s. Population and Development Review 6(1), 65-93.

Frejka, T. and G. Calot (2001a). Cohort reproductive patterns in low-fertility countries. Population and Development Review 27(1), 103-132.

Frejka, T. and G. Calot (2001b). Lévolution du calendrier des naissances par génération dans les pays á basse fécondité á la fin du xxe siècle. Population 56(3), 397-420.

Gauthier, A. H. (2001). The impact of public policies on families and demographic behaviour. Paper presented at the EURESCO Conference on the Second Demographic Transition, Bad Herrenhalb, Germany, June 23-28 (available at http://www.demogr.mpg.de/Papers/workshops).

Giannelli, G. C. and C. Monfardini (2000a). Joint decisions on household membership and human capital accumulation of youths. IZA Discussion Paper No. 191, Bonn. 
Giannelli, G. C. and C. Monfardini (2000b). A nest or a golden cage? Family co-residence and human capital investment decisions of young adults. International Journal of Manpower 21(3-4), 227-245.

Glass, D. V. (1936). The Struggle for Population. Oxford: Clarendon Press.

Goldin, C. and L. F. Katz (2000). The power of the pill: Oral contraceptives and woment's career and marriage decisions. NBER Working Paper No. 7527.

Golini, A. (1998). How low can fertility be? an empirical exploration. Population and Development Review 24(1), 59-74.

González, M. J., T. Jurado, and M. Naldini (2000). Introduction: Interpreting the transformation of gender inequalities in Southern Europe. In M. J. González, T. Jurado, and M. Naldini (Eds.), Gender Inequalities in Southern Europe.Women, Work and Welfare in the 1990s. London: Frank Cass.

Grootaert, C. and J. Braithwaite (1998). Poverty correlates and indicator-based targeting in Eastern Europe and the former Soviet Union. The World Bank, Policy Research Working Paper No. 1942.

Grossard-Shechtman, A. (1985). Marriage sqeezes and the marriage market. In K. Davis (Ed.), Contemporary Marriage: Comparative Perspective on a Changing Institution, pp. 375-395. New York: Russel Sage Foundation.

Guiso, L. and T. Jappelli (1999). Private transfers, borrowing constraints and the timing of homeownership. ISAE (Institute for Studies and Economic Analysis), Working Paper No. 5.

Gustafsson, S. S. (2001a). Optimal age at giving birth: Theoretical and empirical considerations on postponement of maternity in Europe. Journal of Population Economics $14(2), 225-247$.

Gustafsson, S. S. (2001b). Optimal age at motherhood.theoretical and empirical considerations on postponement of maternity in Europe. Journal of Population Economics 14(2), $225-247$.

Haines, M. R. (1992). Occupation and social class during fertility decline: Historical perspectives. In J. R. Gillis, L. A. Tilly, and D. Levine (Eds.), The European Experience of Declining Fertility, 1850-1970: The Quiet Revolution, pp. 193-226. Cambridge, Massachusetts: Blackwell.

Hajnal, J. (1965). European marriage pattern in perspective. In G. D. V. and D. E. Eversley (Eds.), Population in History: Essays in Historical Demography, pp. 101-143. Chicago, Illinois: Aldine Publishing Company.

Hajnal, J. (1982). Two kinds of preindustrial household formation systems. Population and Development Review 8(3), 449-494. 
Happel, S. K., J. K. Hill, and S. A. Low (1984). An economic analysis of the timing of childbirth. Population Studies 38, 299-311.

Heckhausen, J. (1999). Developmental Regulation in Adulthood: Age-Normative and Sociostructural Constraints as Adaptive Challenges. Cambridge: Cambridge University Press.

Hobcraft, J. (1996). Fertility in England and Wales: A fifty-year perspective. Population Studies 50(3), 485-524.

Hotz, J. V. and R. A. Miller (1988). An empirical analysis of life cycle fertility and female labour supply. Econometrica 56(1), 91-118.

Johansson, S. R. (1987). Status anxiety and demographic contraction of privileged populations. Population and Development Review 13(3), 439-470.

Kaufert, P. A., P. Gilbert, and R. Tate (1987). Defining menopausal status: The impact of longitudinal data. Maturitas 9, 217-226.

Kiernan, K. (1999). Childbearing outside marriage in Western Europe. Population Trends 98, 11-20.

Kirk, D. (1946). Europe's Poulation in the Interwar Years. Princeton: Princeton University Press.

Kohler, H.-P. (2000a). Fertility decline as a coordination problem. Journal of Development Economics 63(2), 231-263.

Kohler, H.-P. (2000b). Social interaction and fluctuations in birth rates. Population Studies 54(2), 223-238.

Kohler, H.-P. (2001). Fertility and Social Interactions: An Economic Perspective. Oxford: Oxford University Press.

Kohler, H.-P., J. R. Behrman, and S. C. Watkins (2000). Empirical assessments of social networks, fertility and family planning programs: Nonlinearities and their implications. Demographic Research (Online available at http://demographic-research.org) 3(7).

Kohler, H.-P., J. R. Behrman, and S. C. Watkins (2001). The density of social networks and fertility decisions: Evidence from South Nyanza District, Kenya. Demography 38(1), $43-58$.

Kohler, H.-P. and I. Kohler (1999). Fertility Decline in Russia: Social versus Economic Factors. Max Planck Institute for Demographic Research, Rostock, Germany, Working Paper \#2001-013 (available at http://www.demogr.mpg.de).

Kohler, H.-P. and J. A. Ortega (2001a). Adjusting period fertility measures for tempo distortions using occurrence-exposure rates. Max Planck Institute for Demographic Research, Rostock, Germany, Working Paper \#2001-001 (available at http://demogr.mpg.de). 
Kohler, H.-P. and J. A. Ortega (2001b). Period parity progression measures with continued fertility postponement: A new look at the implications of delayed childbearing for cohort fertility. Max Planck Institute for Demographic Research, Rostock, Germany, Working Paper \#2001-001 (available at http://www.demogr.mpg.de).

Kohler, H.-P. and J. A. Ortega (2001c). Period parity progression measures with continued fertility postponement: Assessing the implications of delayed childbearing for fertility in sweden, the netherlands and spain. Paper presented at the IUSSP conference on Low Fertility: Trends, Theories and Policies, Tokyo, March 21-23.

Kohler, H.-P. and D. Philipov (2001). Variance effects in the Bongaarts-Feeney formula. Demography 38(1), 1-16.

Kohler, H.-P., J. L. Rodgers, and K. Christensen (1999). Is fertility behavior in our genes: Findings from a Danish twin study. Population and Development Review 25(2), $253-288$.

Kohler, H.-P., A. Skytthe, and K. Christensen (2001). The age at first birth and completed fertility reconsidered: Findings from a sample of identical twins. Max Planck Institute for Demographic Research, Rostock, Germany, Working Paper \#2001-006 (available at http://www.demogr.mpg.de).

Kohlmann, A. and S. Zuev (2001). Patterns of childbearing in Russia 1994-1998. Max Planck Institute for Demographic Research, Rostock, Germany, Working Paper \#2001018 (available at http://www.demogr.mpg.de).

Korean National Statistical Office (2001). Statistical Database (KOSIS). Available at http://www.nso.go.kr/eng/.

Lassibille, G., L. N. Gómez, I. A. Ramos, and C. D. Sánchez (2001). Youth transition from school to work in Spain. Economics of Education Review 20(2), 139-49.

Lee, R. D. (1980). Aiming at a moving target: Period fertility and changing reproductive goals. Population Studies 34(2), 205-226.

Lee, R. D. (1997). Population dynamics: Equilibrium, disequilibrium, and consequences of fluctuations. In M. R. Rosenzweig and O. Stark (Eds.), Handbook of Population and Family Economics, pp. 1063-1117. Amsterdam: North Holland.

Lesthaeghe, R. (1983). A century of demographic and cultural change in Western Europe: An exploration of underlying dimensions. Population and Development Review 9(3), $411-435$.

Lesthaeghe, R. and G. Moors (2000). Recent trends in fertility and household formation in the industrialized world. Interface Demography, Department of Social Research, Vrjje Universiteit Brussel, Working Paper IDP-WP-2000-2.

Lesthaeghe, R. and P. Willems (1999). Is low fertility a temporary phenomenon in the European Union. Population and Development Review 25(2), 211-229. 
Livi-Bacci, M. (2001). Too few children and too much family. Daedalus 130(3), 139-156.

Lokshin, M. and M. Ravallion (2000). Short-lived shocks with long-lived impacts? Household income dynamics in a transition economy. The World Bank, Policy Research Working Paper No. 2459.

Lokshin, M. M. and R. Yemtsov (2001). Household strategies for coping with poverty and social exclusion in post-crisis Russia. The World Bank, Policy Research Working Paper No. 2556.

Luttmer, E. F. P. (2001). Measuring poverty dynamics and inequality in transition economies: Disentangeling real events from noisy data. The World Bank, Policy Research working paper No. 2549.

Macunovich, D. J. (1998). Fertility and the Easterlin hypothesis: An assessment of the literature. Journal of Population Economics 11, 53-111.

Macura, M. (2000). Fertility decline in the transition economies. In UN ECE (Ed.), Economic Survey in Europe, 2000/1, pp. 189-207. Geneva: United Nations, Economic Commission for Europe.

Marini, M. M. and P. J. Hodsdon (1981). Effects of the timing of marriage and first birth on the spacing of subsequent births. Demography 18(4), 529-548.

Martikainen, P. T. and T. Valkonen (1998). The effects of differential unemployment rate increases of occupation groups on changes in mortality. American Journal of Public Health 88(12), 1859-1861.

McDonald, P. (2000). Gender equity in theories of fertility transition. Population and Development Review 26(3), 427-440.

Menken, J. (1985). Age and fertility: How late can you wait? Demography 22(4), 469-483.

Milanovic, B. (1998). Income, inequality, and poverty during the transition from to market economy. Washington, DC: The World Bank.

Montgomery, M. R. and J. B. Casterline (1996). Social influence, social learning, and new models of fertility. Population and Development Review 22(Suppl.), 151-175.

Morgan, P. S. and R. R. Rindfuss (1999). Reexamining the link of early childbearing to marriage and to subsequent fertility. Demography 36(1), 59-75.

Morgan, S. P. and R. B. King (2000). Why have children in the 21st century? Biological predispositions, social coercion, rational choice. European Journal of Population 17(1), $3-20$.

Munich, D., J. Svejnar, and K. Terrell (1999). Return to human capital under the communist wage grid and during the transition to a market economy. Journal of Comparative Economics 27, 33-60. 
Newell, A. and B. Reilly (2000). Rates of return to educational qualifications in the transitional economies. Education Economics 7(1), 67-83.

Noorkoiv, R., P. F. Orazem, A. Puur, and M. Vodopivec (1997). How Estonias economic transition affected employment and wages. The World Bank, Policy Research Working Paper No. 1837.

O'Connor, K. A., D. J. Holman, and J. M. Wood (1998). Declining fecundity and ovarian ageing in natural fertility poulations. Maturitas 30, 127-136.

Oppenheim Mason, K. (1983). Norms relating to the desire for children. In R. A. Bulatao and R. D. Lee (Eds.), Determinants of Fertility in Developing Countries, Vol. 1., pp. 388-428. London: Academic Press.

Orazem, P. F. and M. Vodopivec (1995). Winners and loosers in transition: Returns to education, experience and gender in Slovenia. World Bank Economic Review 9(2), 201-230.

Orazem, P. F. and M. Vodopivec (1999). Male-female differences in labor market outcomes during the early transition to market: The case of Estonia and Slovenia. The World Bank, Policy Research Working Paper No. 2087.

Ortega, J. A. and H.-P. Kohler (2001). Measuring low fertility. Mimeo, Max Planck Institute for Demographic Research, Rostock, Germany.

Ortega-Osona, J. A. and H.-P. Kohler (forthcoming). ?'Está cayendo realmente la fecundidad española? Separación de los efectos intensidad, calendario y varianza en el índice sintético de fecundidad. Revista Española Internacional de Sociología, forthcoming.

Palomba, R. and L. L. Sabbadini (1993). Female life strategies: the way of compromise. Proceedings of the XXIII IUSSP General Conference, Montreal 2, 219-231.

Paternostro, S. and D. E. Sahn (1999). Wage determination and gender discrimination in a transition economy: The case of Romania. The World Bank, Policy Research Working Paper No. 2113.

Philipov, D. (2001). Low fertility in Central and Eastern Europe: Culture or economy? Paper presented at the IUSSP Seminar on International Perspectives on Low Fertility: Trends, Theories and Policies. Tokyo, Japan, March 21-23.

Philipov, D. and H.-P. Kohler (2001). Tempo effects in the fertility decline in Eastern Europe: Evidence from Bulgaria, the Czech Republic, Hungary, Poland, and Russia. European Journal of Population 17(1), 37-60.

Presser, H. B. (1971). The timing of the first birth, female roles and black fertility. Milbank Memorial Fund Quarterly 49, 329-362.

Ranjan, P. (1999). Fertility behaviour under income uncertainty. European Journal of Population 15(1), 25-43. 
Reher, D. (1997). Perspectives on the family in Spain, Past and Present. Oxford: Oxford University Press.

Rodgers, J. L., H.-P. Kohler, K. Kyvik, and K. Christensen (2001). Behavior genetic modeling of human fertility: Findings from a contemporary Danish twin study. Demography 38(1), 29-42.

Rutkowski, J. (1996). High skill pay off: The changing wage structure during economic transition in Poland. Economics of Transition 4(1), 89-111.

Ryder, N. B. (1980). Components of temporal variations in American fertility. In R. W. Hiorns (Ed.), Demographic Patterns in Developed Societies, pp. London. London: Taylor \& Francis.

Sá, C. and M. Portela (1999). Working and studying: What explains youngsters decisions. Luxembourg Employment Study, Working Paper No. 15.

Saget, C. (2001). Can the level of employment be explained by GDP growth in transition countries? Labour 14(4), 623-644.

Sánchez-Albornoz, N. (1974). The Population of Latin America: A History. Berkeley: University of California Press.

Sandberg, J. F. and S. L. Hofferth (2001). Changes in children's time with parents: United States, 1981-1997. Demography 38(3), 423-436.

Sanderson, W. C. (1991). Below-replacement fertility in nineteenth century America. Population and Development Review 13(2), 305-313.

Sardon, J.-P. (2000). The demographic situation of Europe and the developed countries overseas. Population: An English Selection 12, 293-328.

Settersten, R. A. and G. O. Hägestad (1996). What's the latest? Cultural age deadlines for family transitions. The Gerontologist 36(2), 178-188.

Spinelli, A., I. F. Talamanca, and L. Lauria (2000). Patterns of contraceptive use in 5 European countries. European study group on infertility and subfecundity. American Journa of Public Health 90(9), 1403-1408.

Stark, L. and H.-P. Kohler (2000). The Public Perception and Discussion of Falling Birth Rates: The Recent Debate Over Low Fertility in the Popular Press. Max Planck Institute for Demographic Research, Rostock, Germany, Working Paper \#2000-009 (available at http://www.demogr.mpg.de).

Statistics Bureau \& Statistics Center (2001). Japan Statistical Yearbook. Statistics Bureau \& Statistics Center, Japan (Online at http://www.stat.go.jp).

te Velde, E., M. Dorland, and F. Broekmans (1998). Age at menopause as a marker of reproductive ageing. Maturitas 30, 119-125. 
Teitelbaum, M. (1999). Sustained below-replacement fertility in Europe. Population Bulletin of the United Nations 40/41, 161-183.

Teitelbaum, M. S. and J. Winter (1985). The Fear of Population Decline. London: Academic Press.

Trussell, J. and J. Menken (1978). Early childbearing and subsequent fertility. Family Planning Perspectives 10(4), 209-218.

United Nations (1996). World population prospects: The 1996 Revision. United Nations, Department of Economic and Social Affairs, Population Division.

United Nations (1999). Future expectations for below-replacement fertility. Population Bulletin of the United Nations 40/41, 137-160.

van de Kaa, D. J. (1987). Europe's second demographic transition. Population Bulletin 42(1), 1-59.

van Imhoff, E. (2001). On the impossibility of inferring cohort fertility measures from period fertility measures. Demographic Research [Online available at http://demographicresearch.org] 5(2).

van Imhoff, E. and N. Keilman (2000). On the quantum and tempo of fertility: Comment. Population and Development Review 26(3), 549-553.

Van Noord, P. A. H., J. Dubas, M. Dorland, H. Boersma, and E. R. te Velde (1997). Age at natural menopause in a population-based screening cohort: the role of menarche, fecundity, and lifestyle factors. Fertility and Sterility 68, 95-102.

van Zonneveld, P., G. J. Scheffer, F. J. M. Broekmans, and E. te Velde (2001). Hormones and reproductive aging. Maturitas 38(1), 83-91.

Vercernik, J. (1995). Changing earning distribution in the Czech Republic: Survey evidence from 1988-1994. Economics of Transition 3(3), 355-371.

Watkins, S. C. (1990). From local to national communities: The transformation of demographic regimes in Western Europe, 1870-1960. Population and Development Review $16(2), 241-272$.

White, J. M. (1998). The normative interpretation of life course event histories. Marriage and family review $27(3 / 4), 211-235$.

Wilcox, A. J., C. R. Weinberg, J. F. O'Connor, D. D. Baird, J. Schatterer, R. Canfield, E. G. Armstrong, and B. C. Nisula (1988). Incidence of early loss in pregnancy. New England Journal of Medicine 319, 189-194.

Willis, R. J. (1973). A new approach to the economic theory of fertility behaviour. Journal of Political Economy 81(2, pt. 2), 14-64. 
Wilmoth, J. R. and S. Horiuchi (1999). Rectangularization revisited: variability of age at death within human populations. Demography 36(4), 475-495.

Wilson, C. (2001). Implications of global demographic convergence for fertility theory. Population and Development Review 27(1), 155-172.

Witte, J. C. and G. G. Wagner (1995). Declining fertility in East Germany after unification: A demographic response to socioeconomic change. Population and Development Review 21(2), 387-397.

Wolpin, K. I. (1984). An estimable dynamic stochastic model of fertility and child mortality. Journal of Political Economy 92(5), 852-874.

Young, H. P. (1993). The evolution of conventions. Econometrica 61(1), 57-84.

Zakharov, S. V. and E. I. Ivanova (1996). Fertility decline and recent changes in Russia: On the threshold of the second demographic transition. In J. Da Vanzo and G. Farnsworth (Eds.), Russia's Demographic Crisis, pp. 36-83. Santa Monica: RAND Converence Proceeding.

Zhao, Z. (2001). Low fertility in urban China. Paper presented at the IUSSP Seminar on International Perspectives on Low Fertility, Tokyo, March 21-23. 